B 436215

THE RELATION OF

APPLIED SCIENCE

TO

SUGAR PRODUCTION

IN HAWAII

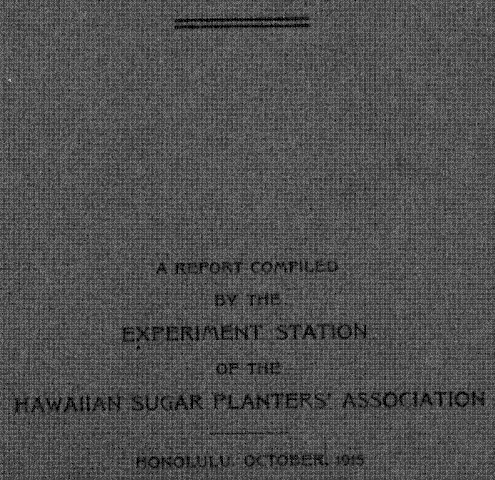




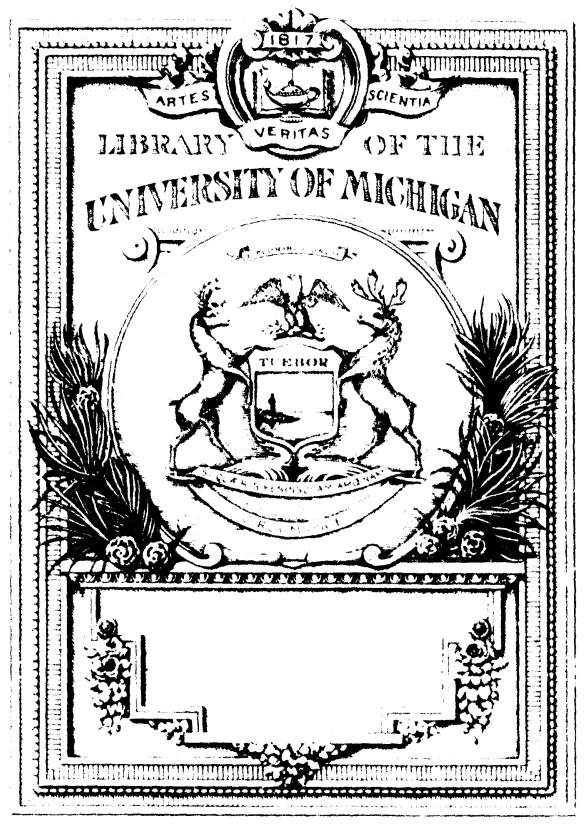






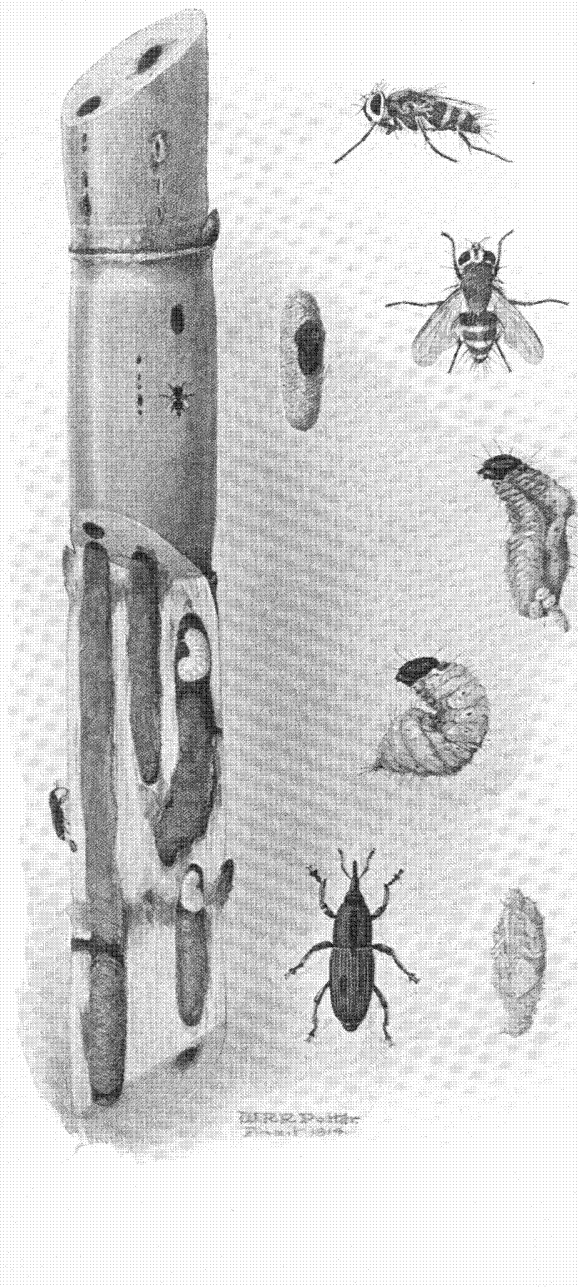




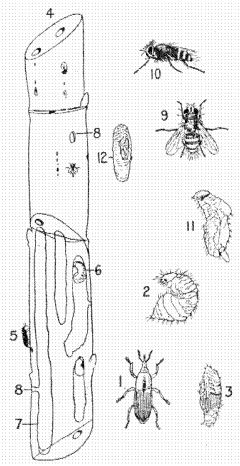

EXPLANATION OF FRONTISPIECE

1. Sugar cane Borer, Rhabdocnemis obscura (Boisd.).

2. Larva of Cane Borer.

3. Pupa of Cane Borer.

4. Piece of cane showing injury by borer.

5. Borer in position for oviposition, an egg showing where it has been inserted in a cavity eaten into the rind.

6. Borer larya in situ.

7. Chamel eaten by borer larva

8. Emergence holes, eaten through the rind by the larva to allow the beetle to emerge from the cane when fully developed.

9. 10. New Guinea Parasite of the cane borer, Ceromasia sphenophori Vill.

11. Borer Iarva with the parasite maggots emerging.

12. Coeoon of borer, showing puparia of parasite inside, 



\title{
THE RELATION OF
} APPLIED SCIENCE

TO

\section{SUGAR PRODUCTION}

\author{
IN HAWAII
}

\author{
A REPORT COMPILED \\ BY THE \\ EXPERIMENT STATION \\ OF THE \\ HAWAIIAN SUGAR PLANTERS' ASSOCIATION, Experiment Station, Nonolulur
} HONOLULU. OCTOBER, 1915 


\section{EXPERIMENT STATION}

OF THE

HAWAIIAN SUGAR PLANTERS' ASSOCIATION

Mr. Frank J. Sheridan,

Special Agent, U. S. Dept. of Commerce.

Dear SIR:-I transmit herewith a paper entitled, "The Relation of Applied Science to Sugar Production in Hawaii."

This has been prepared with the coöperation of Messrs. Burgess, Lyon, Norris, Potter and Swezey of the staff of this Experiment Station, and is intended in some measure to convey to you the information you requested of me.

Respectfully,

H. P. Agee,

Director.

Honolulu, October 15, 1915. 


\section{CONTENTS.}

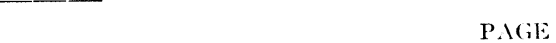

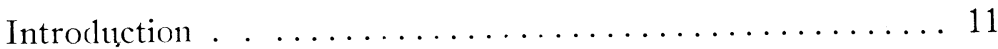

An Outline of the Experiment Station Work......... 27

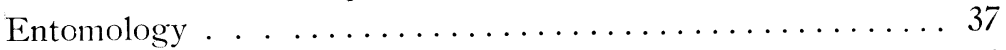

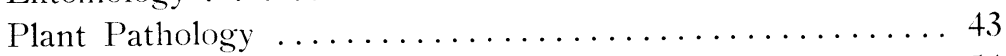

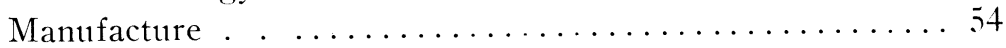

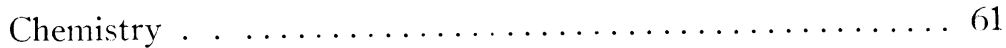

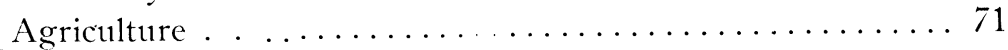

Publications . . ....................... 80 


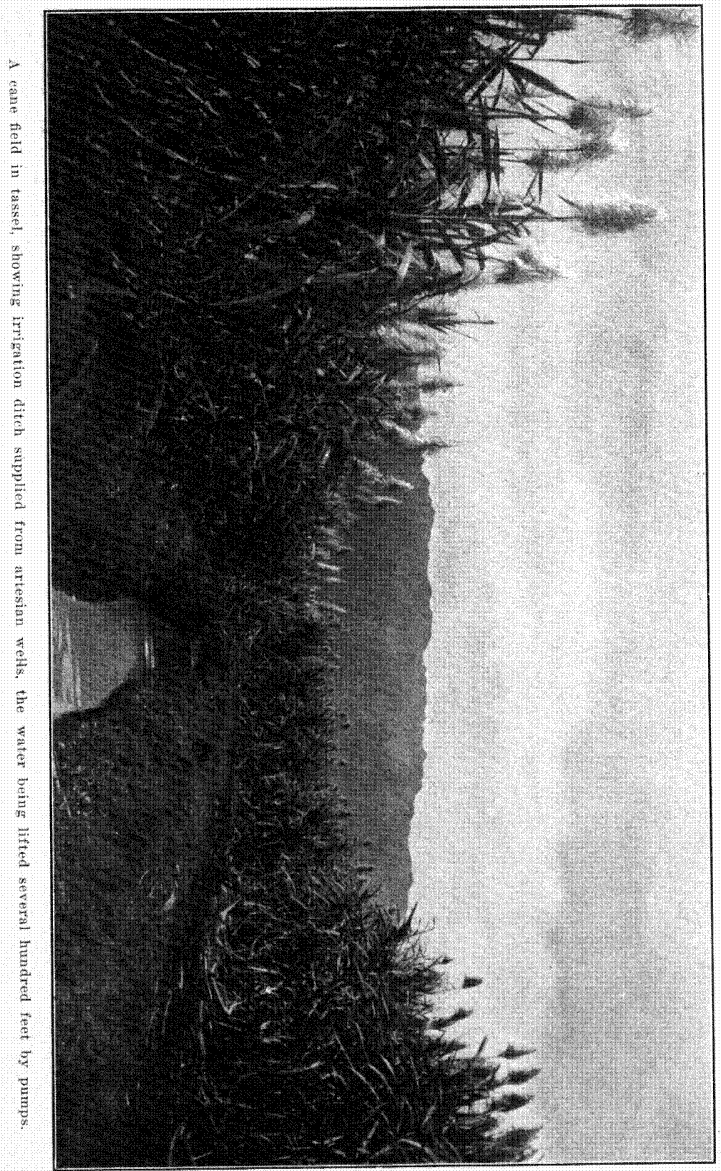




\section{The Relation of Applied Science to Sugar Production in Hawaii}

\section{INTRODUCTION.}

Hawaii ranks third among the countries supplying cane sugar to the markets of the world. Cuba and Java take first and second place.* That the output of both Culba and Java is far in excess of that of Hawaii is graphically told by the accompanying chart, and is readily accounted for by the more advantageous conditions under which the industry in these foreign islands is operated.

It might be concluded at first thought, because these three widely separated island localities are to the forefront in catering to the demand for cane sugar, that their success is due to some favored conditions with which they have been endowed in common against the rest of the world lying within equivalent latitules. This is not the case. The cultivable areas of Cuba, Java and Hawaii are but the smallest fraction of the total frost-free tillable areas of the globe. To enter fully into an explanation of why the cane sugar industry has attained ascendancy on these islands would be to trace the sociological and political upheavals that have affected the decline of cane sugar production, first in the countries around the Mediterranean, afterwards in Brazil, San Domingo, the British West Indies and other districts where, to go back to early history, there were promising cane sugar outlooks. It suffices for the present, however, to show that the survival of sugar production in Cuba, in Java, and in Hawaii is due to separate and distinct causes, for the industries of the three districts are built upon totally dissimilar foundations.

The mainstay of sugar production in Culba is the abundance of cheap lands.

The mainstay of sugar production in Java is the abundance of cheap labor.

Hawaii has neither cheap lands nor cheap labor. As a substitute for these she has developed, and must perforce maintain, an efficiency which is well ahead of that of her foreign competitors.

This contention may be emphasized by setting forth a few salient facts picturing the position in which the American islands

\footnotetext{
* British India, which would rank first, exports no sugar, and is therefore omitted from present consideration.
} 
PRODUCTION OF SUGAR IN HAWAII, JAVA, AND CUBA FOR TWENTY YEARS-1895-1914.

\begin{tabular}{|c|c|c|c|}
\hline & Hawaii $\$$ & Java* & Cuba $\dagger$ \\
\hline Year. & Tons (2,000 lbs.) & Tons $(2,000 \mathrm{lbs})$. & Tons $(2,000 \mathrm{lb}$ \\
\hline 1895 & 149,627 & $6+1,069$ & 248,263 \\
\hline 6 & 225,828 & 589,063 & 233,746 \\
\hline 7 & 251,126 & 646,283 & 336,802 \\
\hline 8 & 229,414 & 799,208 & 380,584 \\
\hline 9 & 282,807 & 840,453 & 340,110 \\
\hline 1900 & 289,544 & 820,402 & 705,320 \\
\hline 1 & 360,038 & 885,965 & 942,675 \\
\hline 2 & . 355,611 & 988,915 & $1,101,073$ \\
\hline 3 & . 437,991 & $1,041,466$ & $1,146,654$ \\
\hline 4 & 367,475 & $1,162,984$ & $1,282,271$ \\
\hline 5 & . 426,248 & $1,145,496$ & $1,299,347$ \\
\hline 6 & 429,213 & $1,17 \tau, 044$ & $1,573,738$ \\
\hline$\tau$ & 440,017 & $1,333,935$ & $1,060,376$ \\
\hline 8 & . 521,123 & $1,368,942$ & $1,668,437$ \\
\hline 9 & . . 535,156 & $1,374,867$ & $1,988,952$ \\
\hline 1910 & 517,090 & $1,409,215$ & 1,635,223 \\
\hline 11. & 566,821 & $1,(616,614$ & $2,089,962$ \\
\hline 12 & 595,258 & $1,467,373$ & $2,6 \pi 7,001$ \\
\hline 13 & 546,798 & $1,482,860$ & $2,863,506$ \\
\hline 14. & $\ldots \quad 617,038$ & $1,421,098$ & $2,866,006$ \\
\hline
\end{tabular}

\$ Data for 1895 to 1900 , inclusive, obtained from Planter's Monthly, 1904, p. 492; data for 1901 to 1914 , inclusive, obtained from Manual of $H$. S., 1915, p. 94 .

* Data for 1895 to 1911 , inclusive, obtained from World's Cane Sugar Industry, by Geerligs, p. 121, re-computed into short tons; data for 1912 to 1914 ,

$\dagger$ Data for 1895 to 1913 , inclusive, obtained from Manual of Hawaiian Securities, 1915 , p. 96 -long tons multiplied by 1.10231 ; data for 1914 obtained from International Sugar Journal, July, 1915, p. 341. 


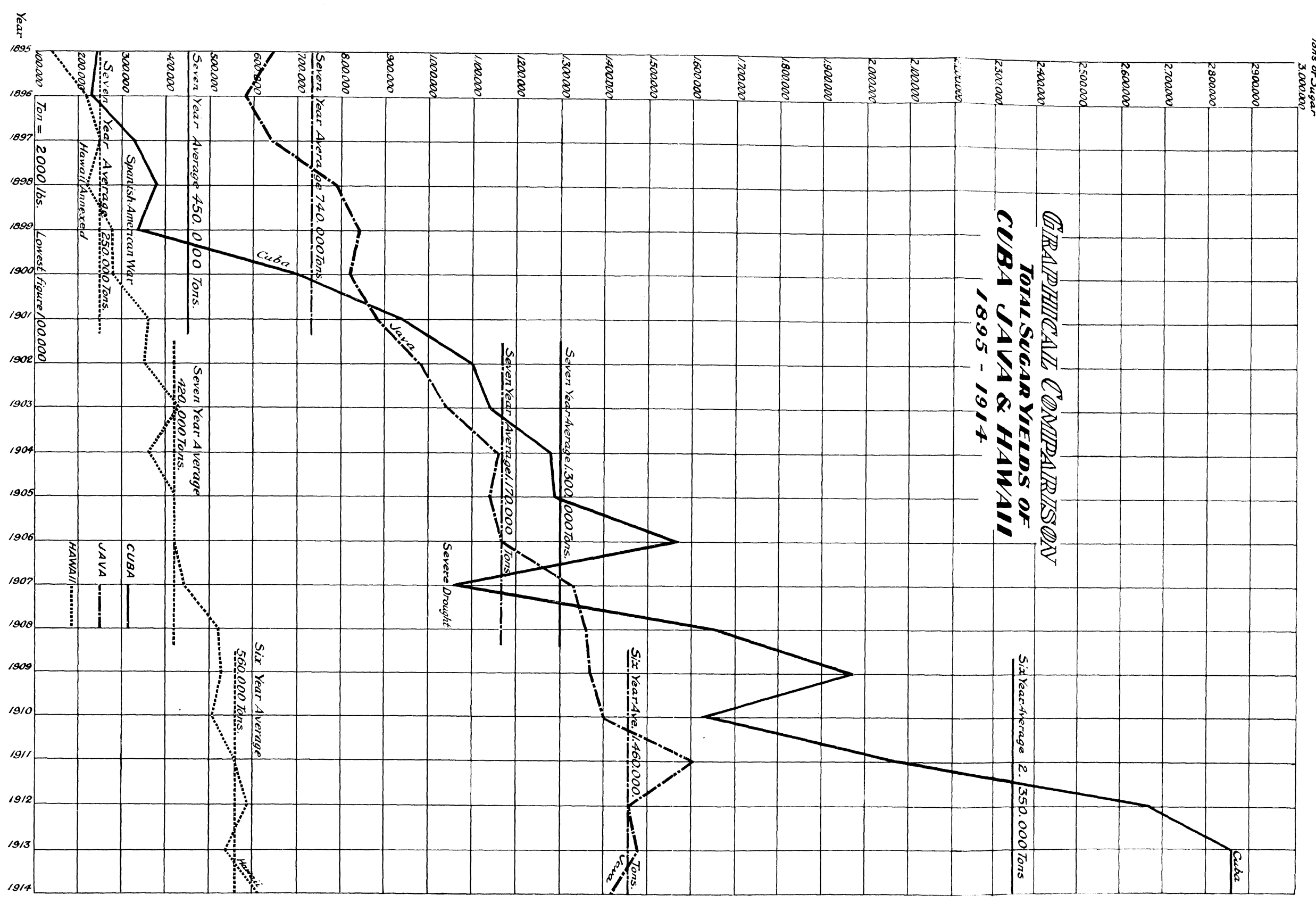

$\left(\begin{array}{l}3 N \\ 3,0 \times\end{array}\right.$ 


$$
\|
$$


are placed in upholding their chief industry. We quote from Geerligs, a world authority on sugar:

It is to be considered a great adrantage for the cuban CUBA. industry that the fertility of the soil allows sugar cane to be treated as though it were a weed which, once planted, wants harlly any further care or treatment."

But little care is bestowed on the planting, and yet the sugar cane once planted yields ample crops for years, and that without any manuring or tillage to speak of. When in the end the cane is considered too old for a further crop, and the old stubbles are removed, the same soil when planted anew will yield again very satisfactory crops for years, and that without any rotation of crops, till finally being exhausted it will be abandonerl and used as pasture land.

After the cane is cut, the stumps are covered with dry leaves to prevent too great an evaporation, and owing to the natural moisture of the ground and the occasional showers the eane will soon shoot up again, and, as a rule, is once more ripe twelve months after the eutting. The sugar content of first and second ratoon canes is supposed to be highest, while after the second ratoons the yield of cane becomes less. Generally five to six ratoons are grown, but very often this number is exceeded as circumstances require. A good erop should yield at least 80,000 arrobas per caballeria $(62,000 \mathrm{lbs}$. or 27.8 tons per acre), although sometimes 100,000 and even 160,000 arrobas are obtained. The average crop is 50,000 arrobas per caballeria (17.33 tons to the acre). As soon as a plot promises no larger a crop than 20,000 arrobas per caballeria (say seven tons to the acre) it is usual to plant anew, providing there is no lack of labour. But when labour is scarce, and it is too late in the season to expect a timely harvest from the eane by the following crushing season, it is better to keep on the same cane for another year as this is more profitable in the end. The same field may happen to yield a crop exceeding 20,000 arrobas, in which case it is kept again for further ratoons, so that at the best of times fields may still yield quite satisfactory crops without requiring any fresh planting, after having been cut uninterruptedly for 30 seasons.',

Field treatment does not amount to much; on some modern estates it simply involves eutting and weeding the grass regularly, and going with a jlough, drawn by oxen, between the rows in orler to loosen the soil after the eutting is clone; but even this loosening of the earth is often neglected, so that reaping the erop is the only treatment the cane plantations regularly witness besides that of planting and weeding.',

The cost price of sugar depends primarily on that of the raw material and on the percentage it yields; and, finally, on the expense of manufacture, packing, and transportation to the harbour. Suppose 100 arrobas of cane have cost the mill $\$ 2.70$, and yield 10 per cent. of sugar, the cost of 1 arroba of sugar in raw material would be $\$ 0.27$; suppose the cost of manufacture to amount to $\$ 0.10$ per arroba, and that of transportation to $\$ 0.05$, then the cost price of sugar delivered in the warehouses on the coast will come to 42 cents per arroba-is. 6d. per cwt., not including interest on amortisation, capital and loans, renewal of machinery, etc. Should all these items be taken into consideration, the total cost price will be from 2 to $21 / 4$ cents per lb., being equiralent 


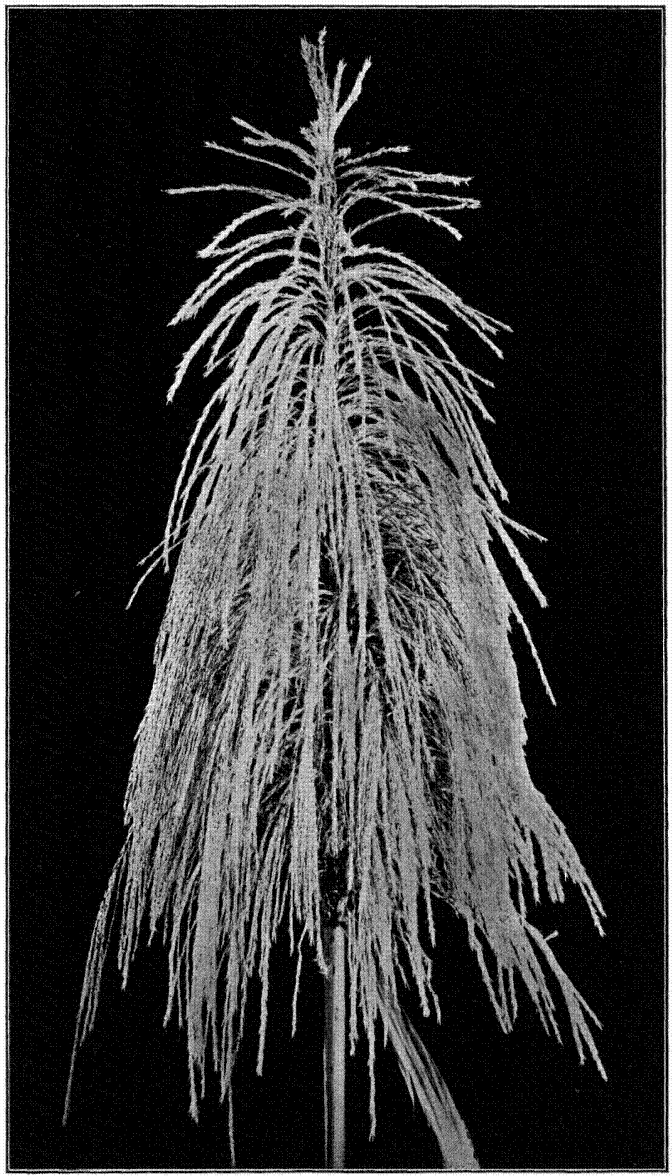

Tassel of Lakaina cane. 
to $9 \mathrm{~s}$. 4d. to $10 \mathrm{~s}$. 6d. per ewt., according to a number of data obtained in 1907 , by the Committee of Ways and Means in the United States."

Doubtless there are estates in which the cost priee is far less, owing to a favourable situation near the sea, which decreases the transportation expenses. Willett and Gray quoted in 1910 as cost price of Cuba sugar at average f. o. b. Cuba 1.85 cents per lb., and at average c. i. f. New York 1.95 cent. They fixed 2 cents per $1 b$. as maximum f. o. b. Cuba cost price, and 1.5 cent per $1 \mathrm{~b}$. as the minimum. Their figures, consequently, are lower on the whoie than those quoted by the manufacturers in 1907.',

The transport cost by railway sometimes forms a considerable part of the expense; it amounts, for instance, to 60 cents a bag of 325 Spanish pounds-that is about 0.2 cents per $1 \mathrm{~b}$, or about $11 \frac{1}{4} \mathrm{~d}$. per cwt.--for all factories which have goods conveyed to the coast by the Cuba Railway Co., irrespective of distance."

Thus Cuba enjoys a low cost of production despite an extensive and inefficient system of agriculture. The laxity of Cuban methods is strongly indicated by the fact that the area under sugar cane in that Island is not definitely known. Such estimates as are published are based on dividing the total production of sugar by an assumed yield per acre. As against this state of affairs in Cuba, where for practical purposes the cane grows wild with little or no cultivation, the industry in Java is founded upon a most elaborate system of hand culture, for cheap labor is a keynote of sugar production in Java. This is clearly shown by the same authority whom we have quoted regarding Cuba :

As compared with most of the other cane-growing colonies, JAVA. where land is abundant and cheap, and labour is scarce and expensive, Java, with its $30,000,000$ inhabitants, wants the land badly for the cultivation of articles of foor, so that the ground disposable for cane growth becomes costly and very limited. On the other hand, this extensive population offers an ample supply of cheap and readily accessible labour, which counter-balances the first-mentioned disadvantage. This explains why it is advisable to proceed in Java quite differently from the manner in which they work in Cuba, and why it is necessary in Java to obtain as much eane, and from the eane as much sugar, as possible through intensive tillage, manuring, eareful up-keep, and constant care; whereas in other countries the quantity of cane produced by a unit of area does not count so much, as there is an abundance of ground to be got for little money.',

As the cane grcus up it is banked with loose soil, which up to that time has been heaped up between the rows. Finally, good care is taken by the time the heavy rains of the west monsoon are due that the cane is entirely banked up, and stands on fairly high banks, so that the rain water ean run off instead of being forced to collect round the roots of the cane. As soon as the cane has ripened, which takes from eleven to fifteen months aecording to the kind of cane and the state of the weather, it is reaped and then lug out as deep as the root. 
Ratoons, as known in most cane sugar producing countries where, in many cases, they are most profitable, are not grown in Java, but every year the past year's crop is reaped, and nothing is kept for a following harvest. This is due to the fact that the first and following ratoons yield so much smaller a crop that, owing to the heavy rent and the small amount of disposable land, it becomes an absolute necessity to obtain as much cane sugar as possible from the little area of land; while labour in Java is so abundant and cheap that it pays well in the end to spend more money on labour connected with the yearly planting.

It is clear that no fixed price of cane can be set down, as the cane production per unit of area varies greatly, and the cost of the different operations for the different parts of the country is not the same either. From a great many annual reports of sugar factories we may infer, however, that the net cost price of cane in the field-that is, without cutting and carting wages, but including the items of land rent, cutting, cultivation, manuring and wages-amounts to $4 \mathrm{~d}$. to $5 \mathrm{~d}$. per pieul, or from 5s. 4d. to 6s. 11d. per ton. Higher and lower figures may occur, but most of the data at our disposal for 1909 vary between these two values.

In the Arehief roor de Jara suikerindustrie, 1908, on page 830, we find the average cost of cane for 1901-1905, on one of the best managed sugar estates in Java, specified as follows:

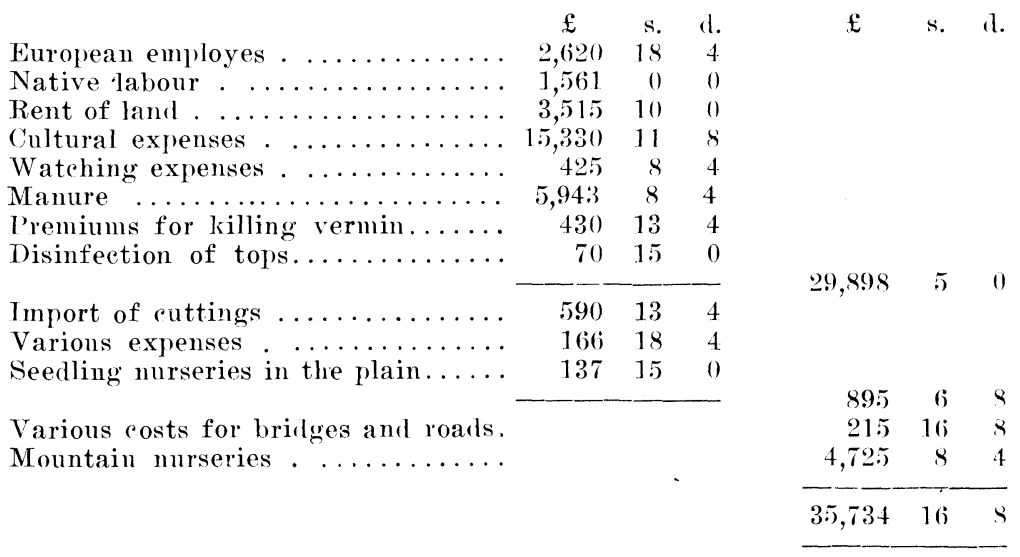

The average planted area amounted for those years to 1,345 bouws $=$ 2,358 acres, so that the total cost of sugar cane in the field per bouw amounted to £26 11s. 8d. (£15 3s. 1d. per acre, or 4s. 9d. per picul cane (6s. 7 d. per metric ton), not including interest, management, taxes, and other expenses.

The prime cost of sugar, first of all depends on the class which is produced, on the cost price and the quality of the cane, on the distance between the factory and the harbour, and also on the factory installation. Generally speaking, it may be taken that the manufacture of superior sugar costs 1s. more than the brown sugar, basis 96.5, and that 


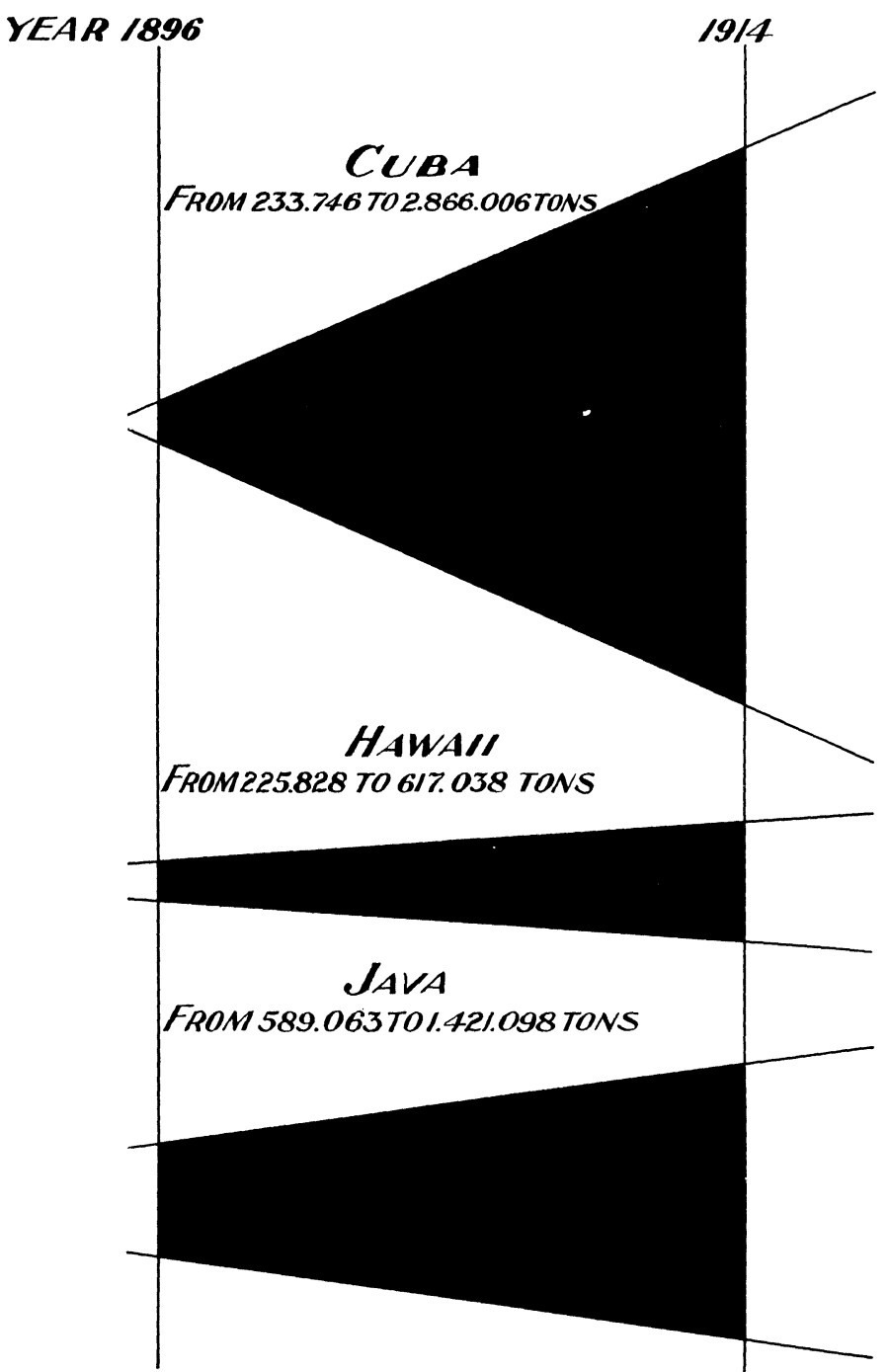

Reference is often made to the impetus which annexation gave the sugar industry of Hawaii. It is interesting to compare this with the advance in sugar production in Cuba following the Spanish. American War, which brought both stable government and trade reciprocity to that island. 
of sugar Nos. 18-20 6d. more per picul-that is allowing for the diminished rendement. But these figures, of course, vary.

H.'s. Jacob published at the same time a specification of the prime cost of sugar, estimated for 212 factories during the years 1899-1902, and arrived at the following figures:

\begin{tabular}{|c|c|c|c|}
\hline & Per Picul. & & er Ton. \\
\hline 189 & & $£ 7$ & $10 \mathrm{~s}$. \\
\hline 1 & . ff 6.27 & $£ 8$ & 11s. $11 \mathrm{~d}$. \\
\hline 190 & .f 6.24 & $£ 8$ & $11 \mathrm{~s}$. \\
\hline 9 & .f 5.59 & $£ 7$ & $13 \mathrm{~s}$. \\
\hline
\end{tabular}

This includes interest on floating eapital, but no interest or mortgage on fixed capital, which really should be added to be exact.

"The amount of $£ 710$ s. $8 \mathrm{~d}$ is specified by him as follows:

\begin{tabular}{|c|c|c|c|c|}
\hline \multirow{4}{*}{$\begin{array}{l}\text { Employes . . . } \\
\text { Agriculture . . } \\
\text { Transport of cane }\end{array}$} & \multirow{2}{*}{$\begin{array}{l}\text { Per Picul. } \\
\text {. f } 0.50\end{array}$} & \multicolumn{3}{|c|}{ Per Ton. } \\
\hline & & $£ 0$ & $12 \mathrm{~s}$. & $5 \mathrm{~d}$. \\
\hline & . ff 2.00 & $£ 2$ & $15 \mathrm{~s}$. & $81 / 2 \mathrm{~d}$. \\
\hline & ff 0.60 & $£ 0$ & $16 \mathrm{~s}$. & $61 / 2 \mathrm{~d}$. \\
\hline$\ldots \ldots \ldots$ & .f 0.07 & $£ 0$ & $1 \mathrm{~s}$. & $11 \mathrm{~d}$. \\
\hline Wages & .f 0.14 & $£ 0$ & $3 \mathrm{~s}$. & $10 \mathrm{~d}$. \\
\hline Sundries. & .ff 0.07 & $£ 0$ & $1 \mathrm{~s}$. & $11 \mathrm{~d}$. \\
\hline Packing . . . . . & .ff 0.16 & $£ 0$ & $4 \mathrm{~s}$. & $41 / 2 \mathrm{~d}$. \\
\hline Transport of sugar & ..f 0.31 & $£ 0$ & $8 \mathrm{~s}$. & $7 \mathrm{~d}$. \\
\hline Maintenance . & .f 0.32 & $£ 0$ & $8 \mathrm{~s}$. & $9 \mathrm{~d}$. \\
\hline Diverse expenses & .ff 0.17 & $£ 0$ & $4 \mathrm{~s}$. & $9 \mathrm{~d}$. \\
\hline Commission . . . & .f 0.27 & $£ 0$ & $7 \mathrm{~s}$. & $6 \mathrm{~d}$. \\
\hline New machinery. & .ff 0.59 & $£ 0$ & $16 \mathrm{~s}$. & $2 \mathrm{~d}$. \\
\hline Interest . . ..... & .f 0.30 & $\mathfrak{£} 0$ & $8 \mathrm{~s}$. & $21 / 2 \mathrm{~d}$. \\
\hline Total & f 5.50 & $£ 7$ & $10 \mathrm{~s}$ & $8 \mathrm{~d}$. \\
\hline
\end{tabular}

The yearly reports of the different joint stock companies give various figures as the cost price of sugar on the several estates, which vary so much as regards the class of sugar, the distance from the seaport, the interest on capital due, the produce, etc., that it is impossible to quote any fixed amount as cost price. Generally speaking, we may consider H.'s. Jacob's figures still to hold good, so that the cost price of the sugar Nos. $11-13$ D. S. comes to $f 5.50$ per picul or $£ 710 \mathrm{~s}$. 8d. per long ton, including all expenses except interest on the capital.

Cuba is, of course, the greatest competitor with American domestic production, but the competition of Java is not to be overlooked on account of its indirect nature. Until recently Java sent considerable amounts of sugar to the American markets, in some years quantities amounting to more than half the production in Hawaii. It is interesting, therefore, to examine certain

* f stands for florin or guilder $=1 \mathrm{~s} .8 \mathrm{~d}$. 
conditions bearing upon sugar production in Java, Cuba and Hàwaii.

The climate of Java is the most tropical and hence the most advantageous for cane culture of the three localities. The average temperature of Java is given at 78.7 ; that of Havana, Cuba, as 75.5 (the average temperature of the cane belt of Cuba is warmer than that of Havana); that of Honolulu as 73 (the climate of Honolulu, on the other hand, is not so cool as the average of the Hawaiian cane areas).

In the matter of topography neither the Cuba nor the Java planters have to contend with the almost mountainous conditions which characterize a large proportion of Hawaii's cane areas.

In point of possible labor supply it is interesting to compare the populations of the three localities. For each ton of sugar produced in Hawaii there is a population of but 0.36 . Although in Cuba scarcity of labor is frequently counted a great check to future development, Cuba has, in fact, more than twice the population-per-ton-of-sugar-produced that Hawaii has: 0.85 against 0.36. Turning to the immense population of Java it is found that there is a population of 20.55 for each ton of sugar producesl.

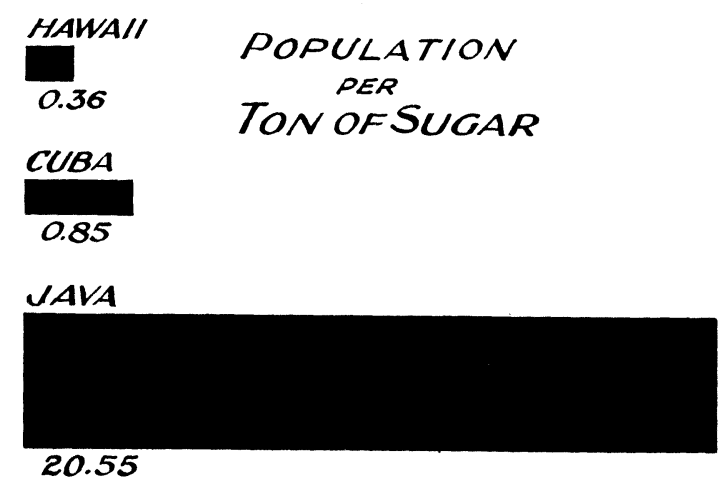

Scarcity of labor is often eited as a drawback to the de. velopment of Cuba's sugar industry, yet Cuba has, in fact, more than twice the population per-ton-of-sugarproduced that Hawai has. ln Java the abundance of cheap labor is a mainstay of sugar production.

If we study these figures in inverse ratio it is apparent that Hawaii annually produces 5,500 pounds of sugar per unit of population, while Cuba produces 2,300 pounds, and Java but 97 pounds per unit of population. 
It appears, therefore, that wherever natural advantages are concerned, Java and Cuba are in the lead, but that in questions of efficiency Hawaii takes first place.

This is further exemplified in studying the production of sugar per acre of land. Hawaii produces 5 tons of sugar per acre; Java, with her superior climate and unlimited supply of labor, 4.5 , while Cuba produces but about 2 to 2.5 tons of sugar per acre.* Of course, if we compare the number of months that have been occupied in growing these crops, the foregoing figures are subject to alteration. It takes all but two full years to make a cane crop in Hawaii, while in Java the time varies from eleven to fifteen months. Cuba usually harvests a crop after an average growth of twelve to fifteen months. But the climatic conditions that necessitate such a long cropping period in Hawaii are a distinct disadvantage, so that a comparison of yields prorated on a unit of cropping time would be distinctly misleading as a gauge of the quality of the agriculture in the three districts.

An interesting comparison has been drawn between the intensive agriculture of Hawaii and mainland standards by Dr Arthur L. Dean. This is given as follows:

"The improved arable land in Hawaii is more intensively cultivated than in any states in the Union. Selecting New York, Illinois, California, Louisiana and the Island of Porto Rico as representative of the various agricultural regions of the United States, and using the statistics of the Thirteenth Census, one may compute the average value of the crops per acre of improved agricultural land. In each case the total value of the crop for the year 1909 is divided by the total acreage of improved agricultural land, giving thereby the average value of the crops per acre. The results, compared with the value for Hawaii obtained in the same manner, are shown as follows:

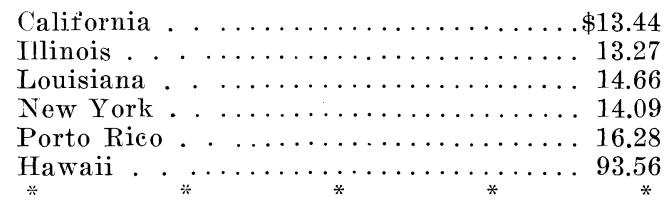

"There is a distinction sharply to be drawn between the production of high erop values and the making of large profits. Hawaii produces

* In arriving at this figure, even approximately, we encounter the difficulty presented by there being no definite data as to the cane area of Cuba. Geerligs gives 829,035 acres as a rough estimate of the area for the crop of 1908-09, but states that "allowance must be made for extensive pastures in use for draught cattle, arable land for the cane planters, and the barren tracts of land in between * * * which results in more than 1,605,500 acres." In an attempt to arrive at the present area under cane we have corresponded with Willett \& Gray, who supply us with the figure $2,500,000$ acres. To use their figure would bring the Cuba yield to about one ton of sugar per acre, which is low, so we have assumed that the Willett \& Gray figure corresponds to the $1,605,500$ offered by Geerligs. If we assume 1,000,000 acres actually under cane, the average output for the last six years would bring the per acre yield to 2.3 . 


$$
11
$$


much per acre-but much goes into the production. On irrigated planta. tions the cost of water alone will equal the total value of an acre of wheat, and on plantations where water must be pumped it will amount to two or three times as much.",

"The Thirteenth ('ensus gives Hawaii's population as 191,909 and the area of improved agricultnral land as 305,053 acres. During the ten years between the census of 1900 and that of 1910 the population increased 24.6 per cent, the area of improved land 3.6 per cent. On the hasis of the 1910 ('ensus we harl 1.586 acres of improved land per person."

"If an agricultural state like North Dakota were supporting as large a population per acre of improved farm land its population wonld number 12900,000 instead of the actual number of $575,(156$. In other words, Hawaii supports twenty-two times as large a population as North Dakota per acre of improved agricultural land.,

"The unique position of Hawaii in the production of wealth per arre is due primarily to the most highly developed, organized, and long rontinuer application of science and husiness efficiency to be found in any large agricultural industry.

As a part of the modern business system responsible for the development of the sugar industry in Hawaii, there are certain matters that the plantations, acting through their Association, have delegated to a central organization, their Experiment Station, which is, in fact, but an arm of the industry itself.

The fight against insect enemies and the control of fungus diseases are matters that lend themselves logically to coöperative action on the part of the planters. Before these branches of work were inaugurated an institution had been formed as early as 1895 to study the island soils and the methods of their treatment. This work has grown with the general adoption of improved methods until today the plantations have assigned to their Experiment Station numerous commissions which in some way or other associate the Station with the greater part of the activities of the industry.

The development of the use of commercial fertilizers and irri gation water, the use of superior varieties of cane, the control of insect pests by their natural enemies or parasites introduced from foreign countries, the study of cane diseases and insect pests occurring in other parts of the world and the rigid quarantine guarding against their introiluction, the control of locai diseases through selected plantings, the development of original methods of agriculture to suit unique conditions, the thorough chemical and engineering control of the factories-in brief, definite attention to fundamental principles, is what singles out sugar production in Hawaii as a striking example of science applied to inclustry. 


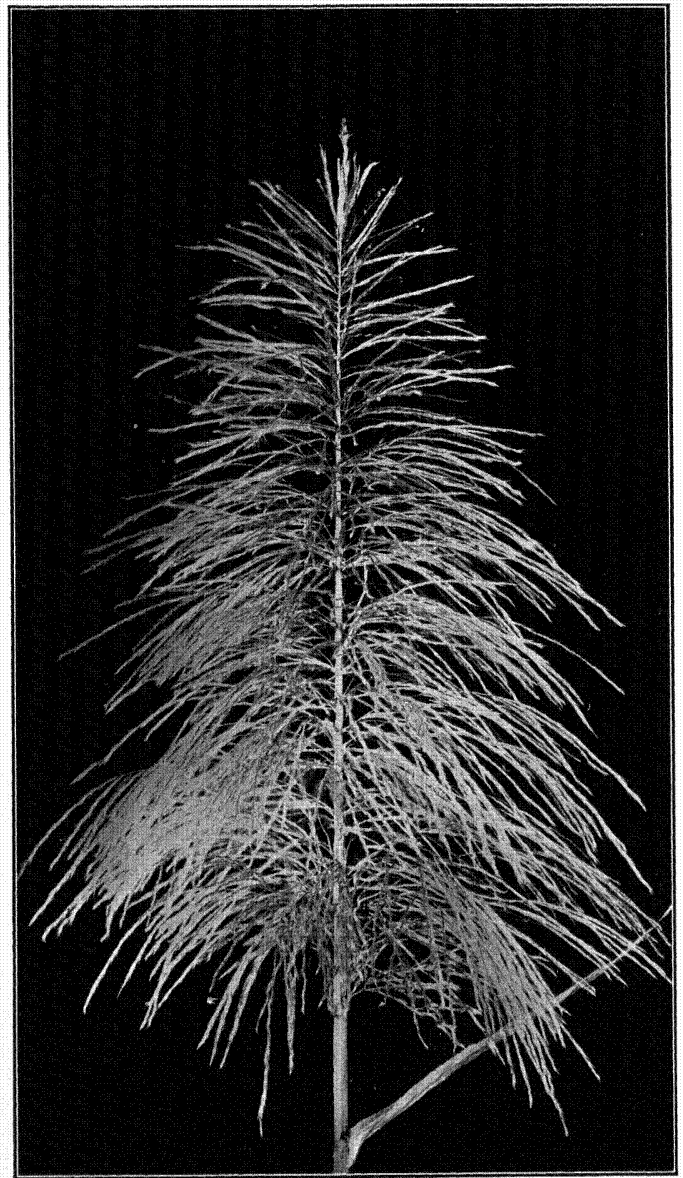

The minute send from these plum-like tassels bave served for the propagation of more than 15,000 new varieties of eane by the Experiment Station. 


\title{
AN OUTLINE OF THE EXPERIMENT STATION WORK.
}

\author{
ENTOMOLOGY.
}

Insect Enemies.

Study of the Habits and Life History of Sugar-Cane Insects :

Anomala, or root grub.

Bud Moth.

Cane Borer.

Cut Worms or Army Worms.

Leaf-hopper.

Leaf-roller.

Mealy bugs.

Miscellaneous insects of minor importance.

Introduction of beneficial insects or parasites.

This work includes the search for these insects in foreign parts, and the breeding of colonies for distribution.

Leaf-hopper parasites, brought from Australia and Fiji.

Hornfly parasites, brought from Europe.

Anomala parasites, brought from Japan and Formosa.

Cane Borer parasites (Tachinid flies), brought from New Guinea.

Miscellaneous parasites of minor importance introduced from various parts of the world.

Plantation Inspections.

General inspections periodically to ascertain general entomological conditions.

Special inspections whenever conditions require investigation, or in connection with the work of spreading parasites or beneficial insects.

Determination and Classification of Insects.

Determination of specimens sent in for identification, or collected by the entomologists.

Systematic work on classification and description of new forms.

Maintenance of Insect Collections.

Economic insects; injurious and beneficial.

Endemic; or native insects.

Foreign; collected on exploration trips for introductions of beneficial insects. 


$$
\|
$$


JLANT PATHOLOGY.

Studies of sugar cane discases and means for their control:

Fiji disease. (A disease which thus far has not entered the islands.)

Iliau.

Leaf-spot diseases.

Eye-spot.

Ring, Spot, etc.

Pahala blight.

Root-rot or "Iahaina disease."

Sereh.

Yellow-stripe disease.

()ther minor diseases, and diseases of plants other than sugar cane, such as Pineapple diseases and Stem-rot of Taro and many others as listed under "Crops other than Sugar Cane."

Economic Fungi.

The study of fungi of benefit to the industry, viz:

Entomogenous fungi, or fungi found useful in controlling insects.

Yeasts used in the fermentation of sugars into alcohol-of interest in view of the proposed manufacture of denatured alcohol from molasses.

CHEMISTRY.

Fertilizers.

Chemical control work consisting of sampling and anlyzing the commercial fertilizers purchased by the plantations, as a check on the manufacturers' guarantees of their composition.

Soils.

Investigation of the types of soils found on the plantations.

Laboratory and lysimeter studies of the effect of commercial fertilizers and other manures on different soils.

Miscellaneous.

General analytical work on samples submitted by the plantations.

MANUFACTURE.

IFactor inspections to check the chemical control of the factory chemists, report on the manufacturing operations, and suggest possible improvements. 


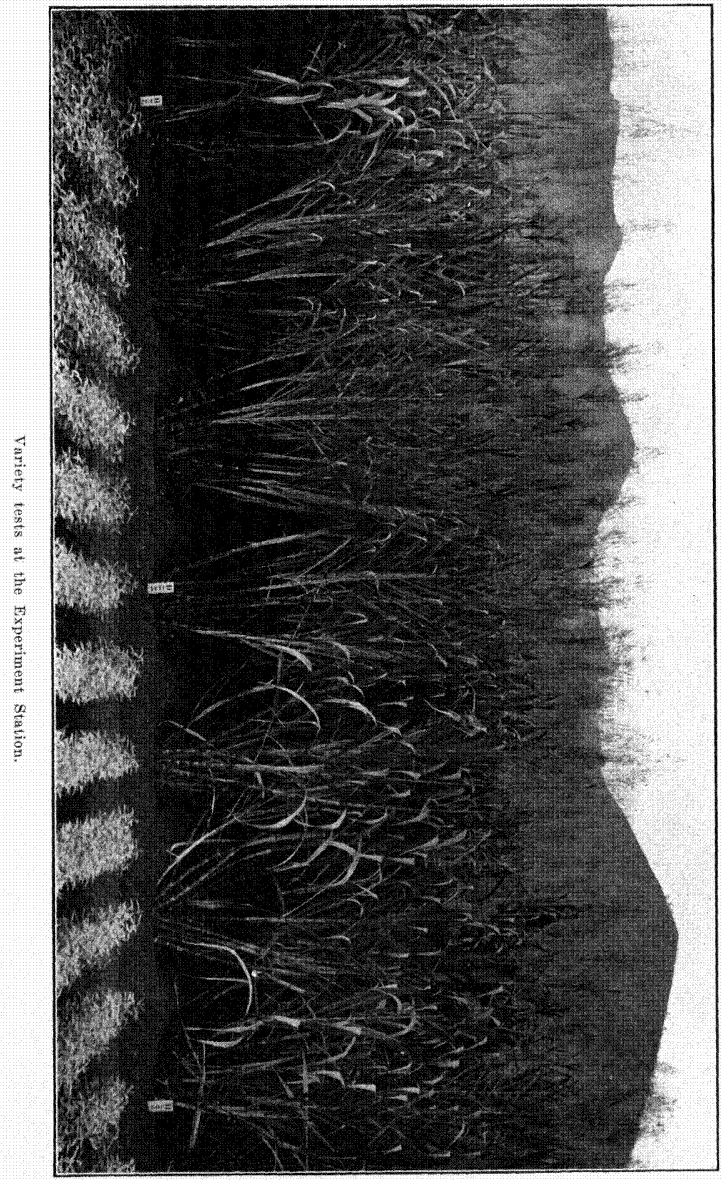


Special inzestigations of specific problems on requests from plantations.

Weekly Mill Reports.

A sheet is published weekly presenting a compilation of the data of the chemical control of manufacture of each of the plantations.

Annual Synopsis of Mill Data.

A similar publication presenting the season's manufacturing results of each factory.

White Sugar Making.

The study of methods to manufacture white sugar.

Miscellaneous.

The study of various problems connected with the manufacture of sugar. AGRICULTURE.

\section{Commercial Fcrtilisers.}

Experiments with regard to use of fertilizers, embracing tests to determine:

The proper composition for maximum yields under different conditions of climate and soil.

The proper methods of applying fertilizer under different conditions of climate and soil.

The relative response of different varieties of cane to given quantities of fertilizers.

The effect of commercial fertilizers on the quality of the juice of the cane.

\section{Cultization.}

Agricultural implements are studied with respect to their comparative merits and suitability to varied conditions.

Methods of cultivation of the different plantations and of foreign cane countries are studied and compared as to their respective merits.

Conservation of organic zuastes, particularly the refuse of the cane crop, is studied with regard to arriving at the most economical means to be employed in this form of soil improvement.

Green Manuring with Legumes.

Introduction and testing of new leguminous plants to find those suited to the different localites. 


$$
\|
$$


Tests to determine practical methods of introducing rotation cropping, or companion cropping with legumes into sugar cane agriculture.

Experiments to determine the benefit resulting from rotation or companion cropping with legumes that have proved suitable to the Island conditions.

\section{Irrigation.}

E.xperiments.

To determine the comparative water requirements of different varieties of cane.

To determine the value of withholding the irrigation water for varying periods on increasing the sugar content of the cane.

\section{Liming.}

Tests to determine the benefit from liming: (1) acid soils; (2) non-acid soils having low lime content.

Tests to compare the relative value of quick lime and coral-sand for the above purposes.

\section{Substations.}

Waipio Substation.

An area of 13.5 acres is devoted to field experiments under practical plantation conditions:

Experiments in varieties.

Experiments in cultivation.

Experiments in fertilization.

Experiments in conserving organic wastes.

Experiments in irrigation.

Plantation Substations.

Experiments on the above stbjects are placed on the plantations to note the effects of variations of climate and soil on different soil treatments.

UTILIZATION OF BY-PRODUCTS.

Paper Making.

Study of the possibilities of bagasse as a paper stock.

Denatured Alcohol.

Study of the practicability of using waste molasses for this purpose, and recovering:

Potash from the waste liquors. 


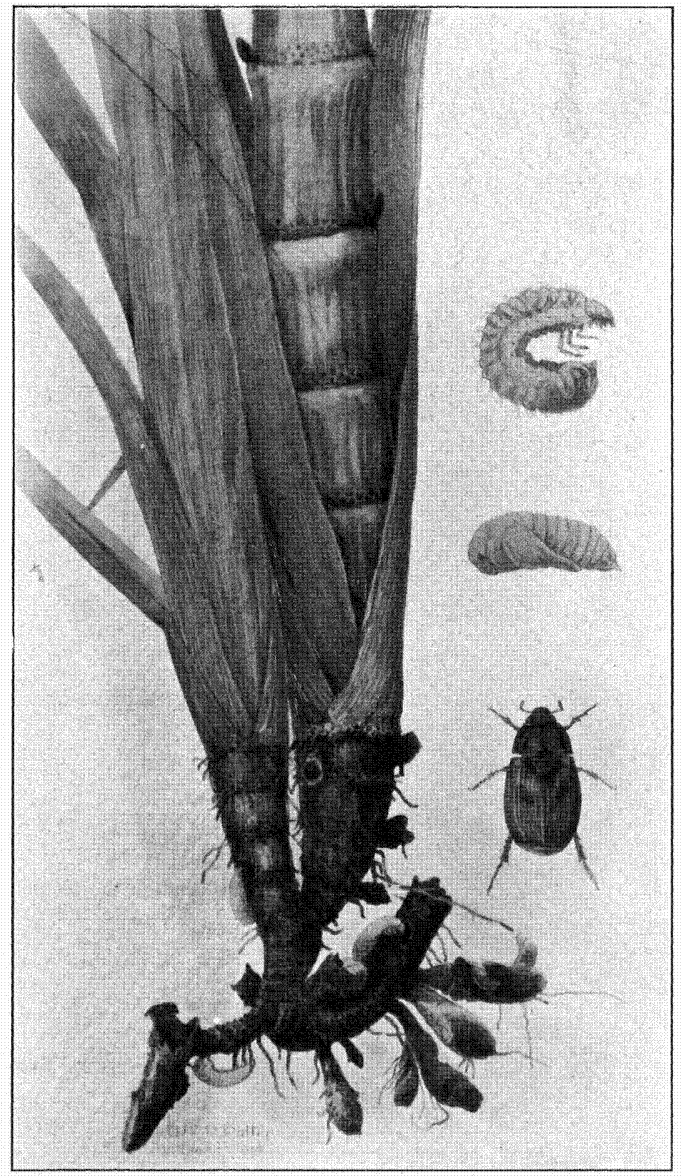

The sugar eane root grub or anomala beetle. A seareh for parasites to control it: is now under way. 
Beef Production.

Study of the practicability of utilizing the cane tops as cattle food and maintaining a beef industry as a side line to sugar production.

CROPS OTHER THAN SUGAR CANE.

Leguminous crops for green manuring. After testing several hundred legumes some four or five were found to give promise under Hawaiian conditions. The seed of these are not to be had in the world markets. With the coopperation of the Federal Experiment Station plans are fostered to have the homesteaders grow this seed to supply the plantations.

Pincapples. The diseases of the pineapple have met attention since 1908. A publication dealing with the pineapple diseases was issued in 1910. At the present time, through an agreement with the Hawaiian Pineapple Packers' Association, a complete survey of the scientific problems of the pineapple industry is under way.

Forestry. Fungus diseases of the Eucalyptus and other forest trees have been studied. An investigation of the dying out of a Maui forest was at one time undertaken.

Miscellaneous crops and plants. The staff of Plant Pathologists has met more outside calls for work on miscellaneous crops than the other departments. No other institution in Hawaii maintains a department of plant pathology. The diseases of many plants have been studied and reported upon. These include, aside from those mentioned above, the following plants: the potato, the sweet potato, taro, banana, orange, papaia, peach, mango, alligator pear, date palm, alfalfa, cotton, vanilla, pepper, oats, barley, wheat, corn, litchi nut, and ornamental plants such as the hibiscus, rose, carnation, etc. 


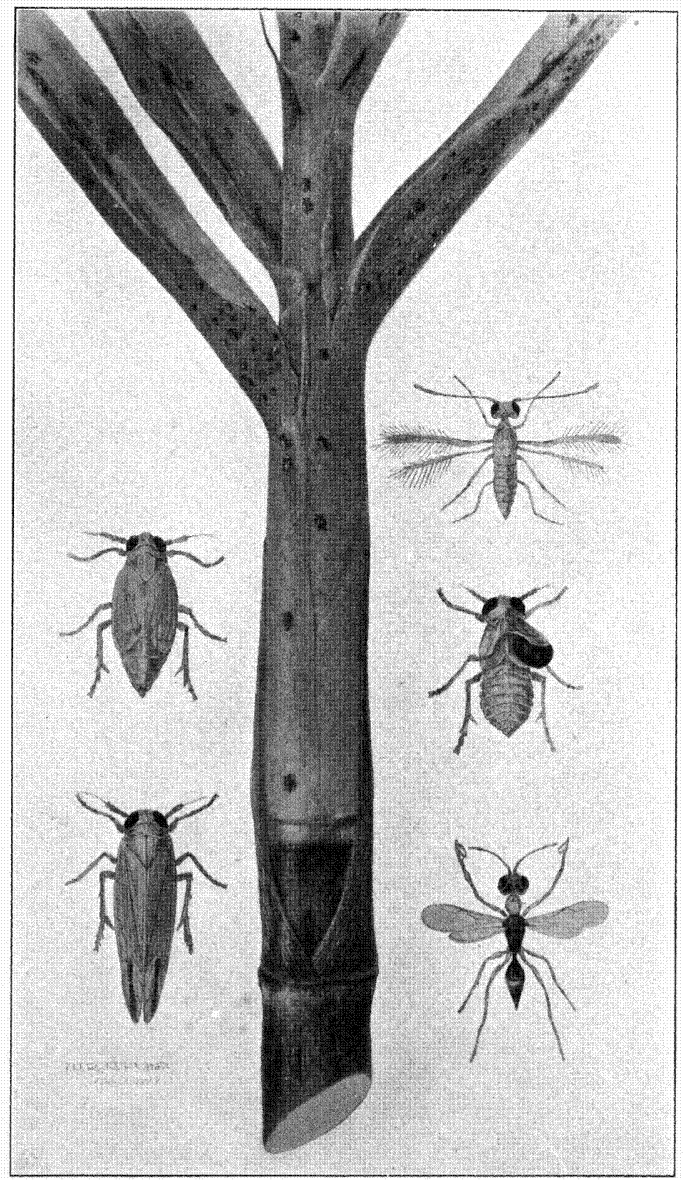

The leaf hopper threatened the indastry with ruin antil cheeked by the introduction of parasites. 


\section{ENTOMOLOGY.}

By O. H. Swezey.

The Entomological Division of the Experiment Station of the Hawaiian Sugar Planters' Association was organized in 1904. The factor most prominent in making the necessity for entomological work by the Experiment Station was the presence of the sugar cane leaf-hopper, prevalent throughout the cane fields of the Hawaiian Islands. This insect had been noticed a few years previously in some of the plantations. It had spread to all of them, and had occasioned great damage in many; in fact, was beginning to cause grave concern among the sugar planters, as it looked for a time as though the industry was threatened with ruin.

The situation being urgent, the Association organized and equipped a department and secured a staff of entomologists to carry on entomological work.

Naturally, as the leaf-hopper was the primal cause for this beginning of entomological work, the entomologists set to work on investigation of its habits, distribution in the Islands, damage to cane, methods of control, etc. At the outset it was recognized that the leaf-hopper was a foreign insect that must have somehow become introduced to the Hawaiian cane fieldsnow considered to have been brought about through the importation of cane cuttings which contained the eggs of the leafhopper, some of which survived the voyage, then hatched and in due time became established at one or more sugar cane districts of the Islands, from which they had become dispersed almost entirely throughout the plantations before attracting any attention.

Investigation of the probable home, or native country, of the leaf-hopper, pointed towards Australia. The insect was not known to be a pest there, however, and so it was thought that there probably were natural enemies there which were responsible for this. Accordingly, two of the entomological staff went to Australia to make a study of the leaf-hopper there, and of its natural enemies, with the purpose of attempting to introduce the latter to Hawaii, if any were found.

As a result of this work, many natural enemies were found, and several species were finally, after various attempts, successfully introduced and established. These, in a few years after being established and widely dispersed, succeeded in checking the leaf-hopper to such an extent that the annual loss was reduced 


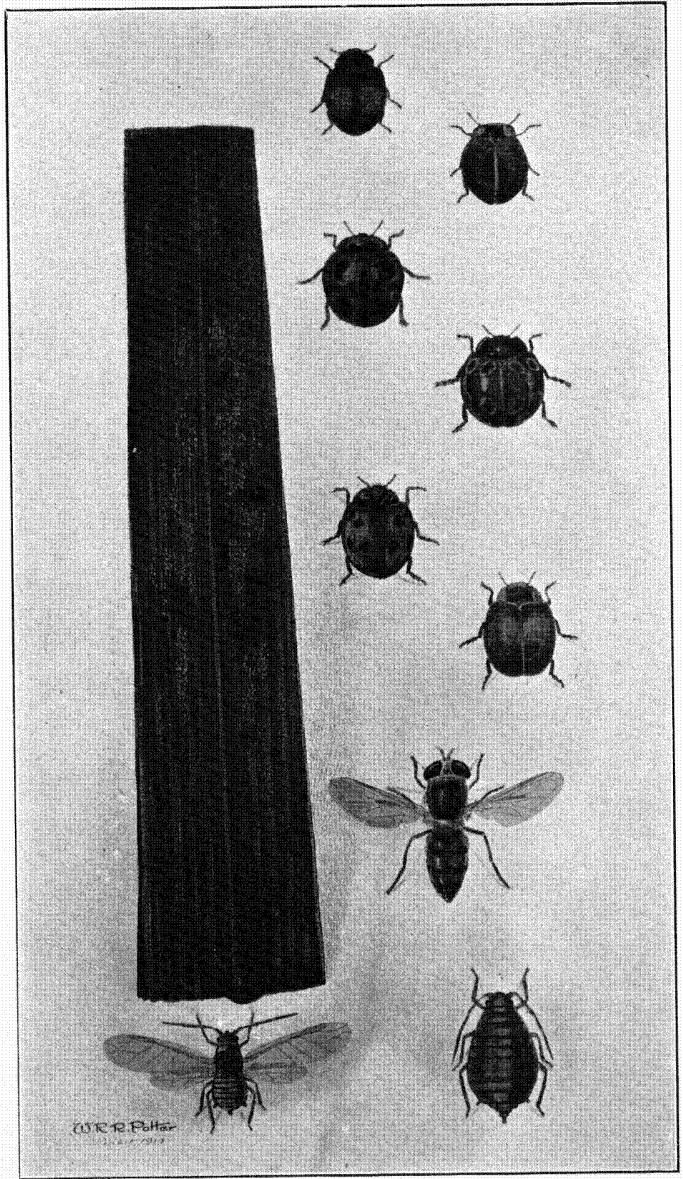

Ladybirds are active in suppressing the sugar eame aphis. 
from $\$ 3,000,000$, as estimated in 1904 , to an almost negligible amount for the most of the cane-growing districts. In some places there is still at times considerable injury by the leafhopper, but not anywhere near the amount resulting formerly, and occurring only in limited areas.

Of the parasites introduced from Australia for the sugar cane leaf-hopper, the most beneficial were egg-parasites; and of these the most important one. Paranagrus optabilis, belongs to the family Mymaridae. It is so small as to escape the notice of all except the entomologists who are familiar with its appearance and habits, and know where to look for it. It is to be found on the leaves of sugar cane which contain leaf-hopper eggs, where it is busily searching for the egg clusters and depositing its own eggs in the eggs of the leaf-hopper. The parasite larva consumes the contents of the leaf-hopper egg in growing to maturity, and completes its transformation to the adlult stage within the host egg, eventually emerging as an aduit insect in the place of the young leaf-hopper which would otherwise have hatched from the egg.

The length of life-cycle of the parasite is about three weeks. which is about one-half that of the leaf-hopper. It is thus enabled to breed and increase more rapidly than its host, and becomes an effective check on the latter. This parasite has been the most important factor in the control of the sugar cane leafhopper; but the other introduced egg-parasites, as well as several native parasites, predaceous insects, and spiders, have played some part.

The staff of entomologists engaged for the above work has been maintained with some changes in the personnel, the number at any one time varying from four to six.

While engaged in the above work with the leaf-hopper and its parasites, investigations were also being macle on other sugar cane pests in Hawaiian cane fields whenever time or convenience permitted. Much information of this character was obtained at the time of periodical inspections conducted for the purpose of keeping informed on leaf-hopper conditions and the distribution of the parasites. Special inspections were also frequently made to investigate special outbreaks of some pest.

Besicles the leaf-hopper, other important sugar cane pests in Hawaii are the weevil borer, leaf-roller, mealybugs, cane aphis, bud-moth, armyworms and cutworms, mole cricket, and a few minor ones that are generally distributed, while another which has but a small local distribution is the cane grub, or Anomala beetle. Nearly all are foreign insects that have become established here through the channels of commerce before the present 


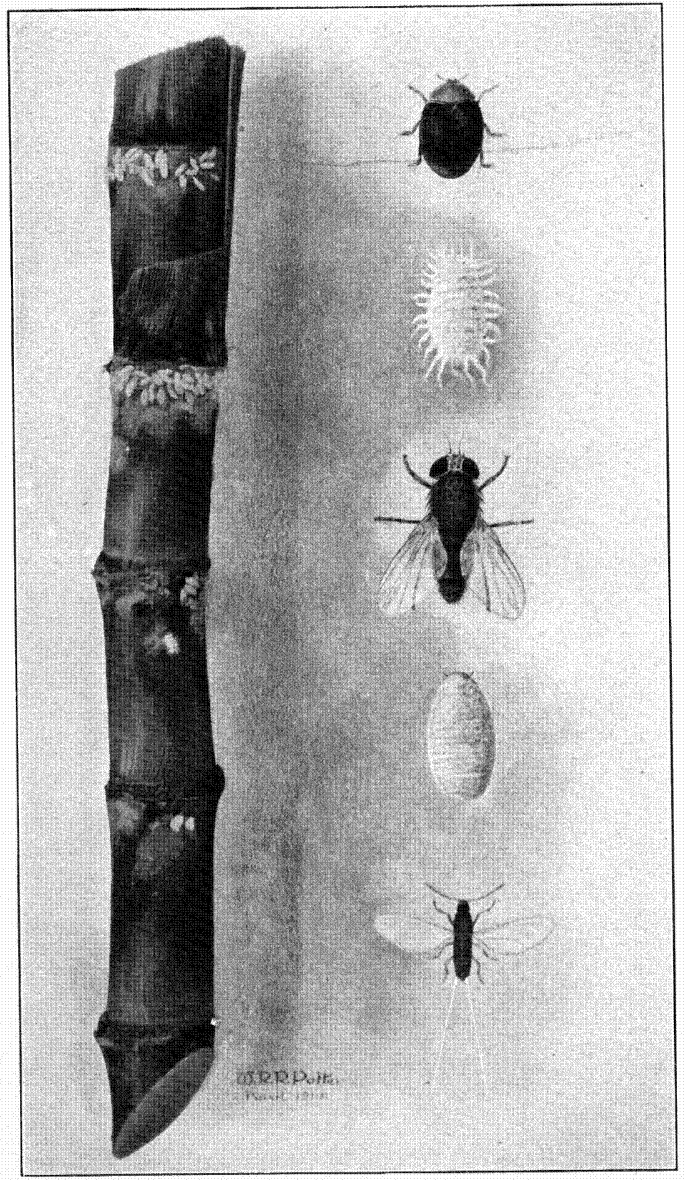

A minor eane pest- the sugar eane mealy bug, and some of its natural enemies. 
efficient system of quarantine inspection was instituted. Of these, the most work has been done on the cane borer. This pest has been present in the lslands for at least fifty years. It has done an enormous amount of damage. Sometimes whole fields would have as much as half the cane injured, and a third or a quarter was often the case. It is impossible to estimate with any accuracy the extent of damage done, but a conservative estimate would be two per cent, which, during the past decade, would have amounted to nearly one million clollars annually.

Several years were spent by one member of the entomological staff in searching for natural enemies of the cane borer, and efforts toward their introduction to Hawaii. Finally, in 1910, a species of Tachinid fly, which was found to be parasitic on the same borer in sugar cane in New Guinea, was successfully introduced in Hawaii. For two years colonies of this fly were bred at the Station and distributed to the sugar plantations. The parasite readily became established and rapidly dispersed throughout the plantations, reducing the borers so that they are no longer to be considered a serious pest.

As an example of the benefits resulting from the checking of the borer by the introduced parasite, on one plantation the yield of sugar per acre was increased by over two tons. This would be 2,000 tons on a plantation harvesting 1,000 acres annually, and would mean $\$ 150,000$ with sugar at $\$ 75$ per ton, or more, according to how much higher is the price per ton. Not all plantations were benefited to this extent, as most were not so badly infested by borers as this one was formerly, but the total saving to the sugar industry of the Islands would amount to a good many thousand dollars annually.

From the beginning, there has been at least one member of the staff almost constantly traveling in some foreign country in search of beneficial insects that might be introduced. Trials have been made with quite a number that have failecl. A few of minor importance have succeeded. At the present time efforts are being made to find and introduce parasites for white grubs, the larvae of Anomala beetle.

As time has allowed, systematic work has been done on collections of insects studied in foreign countries when searching for desirable parasites. Some of the results have been published in bulletins.

The entomological staff has built up a large collection of $\mathrm{Ha}$ waiian insects, including those of economic importance to other crops, as well as those of sugar cane, and any and all insects of interest faunisticly, or otherwise. These are necessary for reference in many ways, as in determining specimens sent in from 


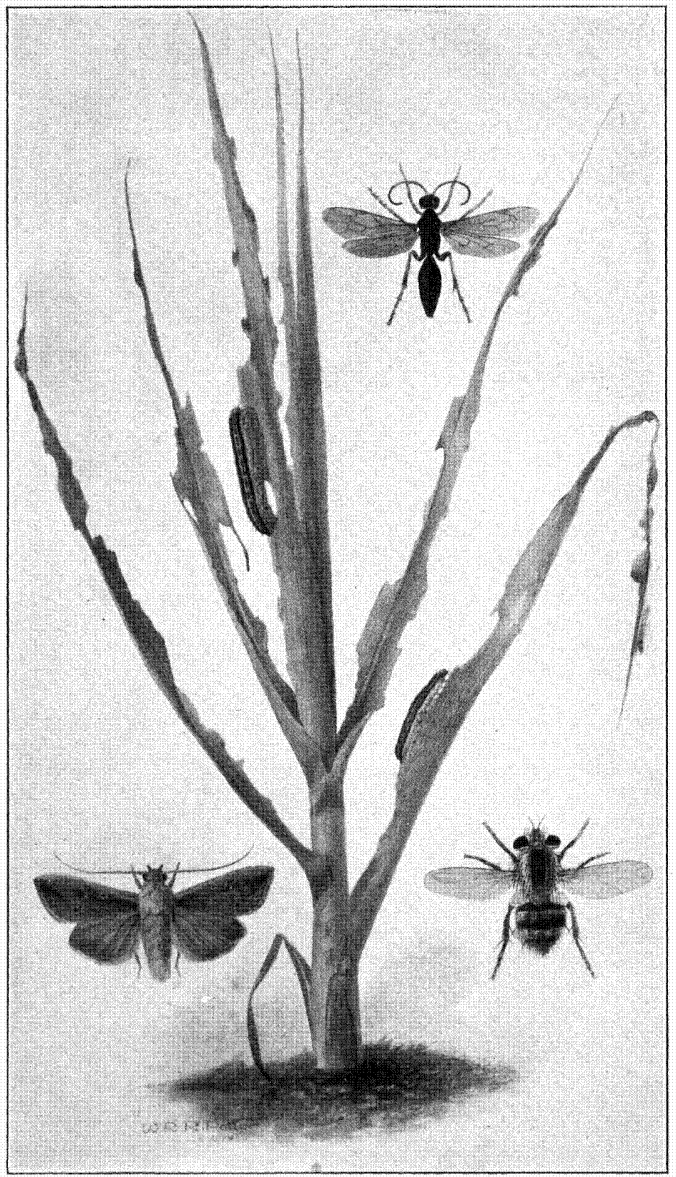

The army worm and its natural enemies 
the plantations, material for systematic study, and ability to recognize any new pest that may at any time turn up. Considerable of the material collected by members of the staff when engaged in parasite investigation in foreign countries has been mounted and arranged in the insect cabinets. Much of this has been worked up, and more will be as opportunity permits. In these cabinets are several hundred "types"; that is, the specimen of insect from which the species was originally describer. The collections are the more valuable on this account.

\title{
PLANT PATHOLOGY.
}

\author{
By H. L. LYON.
}

A solution of sugar is the best all-around culture medium for the cultivation of fungi. It seems to be the one food material on which the majority of fungi can live and flourish. Plain cane juice with its natural impurities better suits the needs of fungi than does refined sugar or the chemically pure product. In fact, all fungi prefer glucose and other invert sugars to sucrose, for they almost always convert sucrose into invert sugars before they can actually feed upon it.

It is rather to be expected, therefore, that the sugar cane plant, with its store of choice, rich juices, will, from time to time, be severely attacked by fungi which learn some method whereby they can force an entrance to its tissues. This conclusion is amply supported by evidence derived from the history of the sugar industry in other countries.

In 1841 a-mysterious "fungoid" disease appeared in the sugar cane of Mauritius and Reunion and almost accomplished the complete elimination of the crop. In 1882 the now famous sereh disease appeared in west Java, and in the course of five years spread over the entire island, bringing their sugar industry to the verge of destruction. In the early nineties the so-called "rinddisease" practically eliminated the Bourbon cane from the West Indies. The sugar planters in that region had grown the Bourbon for upwards of a hundred years, and it ranked as their very best variety.

The cane variety known in Hawaii as Lahaina is identical to the Bourbon of the West Indies. For many years it had been 




Sugax eane affected with fliau. (See foot note on page 45.) 
the favorite cane variety in these Islands, and where it can be grown successfully it is still an excellent variety. About 1900 the Lahaina cane on the Island of Hawaii began to show evidences of disease, and in the course of five years it failed completely on that island and had to be abandoned for other varieties.

A troublesome cane disease had been recognized in Hawaii since the inauguration of the local sugar industry. This disease, christened Iliau by the natives, was known to be responsible for great losses each year; and, in fact, one of the plantations of early days was forced to close down because of the continued heavy losses caused by this disease.

The Hawaiian Sugar Planters were quite familiar with the serious conditions into which the sugar industries of Java, the West Indies and other countries had been thrown by the advent of epidemic diseases among their canes, and, with their own Lahaina cane failing and Ilian causing conspicuous losses in their fields, they founded a department of plant pathology in their Experiment Station in 1905 to aid in coping with problems of this nature.

The investigations conducted by this department have shown that there are, at the present time, nine different fungi which are active parasites on the cane plant in Hawaii. Then, in addition, there are two microscopic round-worms or nematodes which attack the living roots of the cane. Besides the disorders caused by these parasites, our cane is also subject to three serious diseases for which no organic cause has as yet been detected. In addition to the disease-producing organisms, there are a great number of saprophytes which live in intimate relation to the cane plant and require careful watching.

\section{ILIAU.}

Of the fungus diseases, iliau is undoubtedly the most serious and will serve to illustrate the problems presented by a cane disease.

The name iliau is a Hawaiian expression, meaning "tight skin" or "hide bound." It very aptly describes the one conspicuous

Fig. 1. A cane shoot, showing a typieal case of iliau. The outer leaves are already dead and dry, while the leaf-sheaths are firmly cemented together into a hard, unvielding case. The stem tip is so securely bound up by the hardened leaf-bases that it will be unable to make any further growth.

Fig. 2. A cane shoot which managed to grow away from the disease, although at one time badly affected. The iliau fungus actually penetrated the stem and produced severe wounds, which, although not deep, would, nevertheless, render the stem so weak and brittle at this point that it would probably be unable to sustain its own weight when fully grown.

Fig. 3. A short piece from the stem of a shoot which suceumbed to iliau after it had made some two feet of stick. The black dots on the internode are the Melanconium pustules of the iliau fungus. 
symptom of the disease, which is a binding of the leaf bases into a tight, unyielding jacket about the stem. The cane shoot illustrated on page 44, Fig. 1 , is in the condition commonly recognized as a typical case of iliau. The outer leaves are dead and dry, while the leaf-sheaths are firmly cemented together into a hard, unyielding case. The stem-tip is so securely bound up by the hardened leaf-bases that it will be unable to make any further growth and must eventually die as a result. The leaf-sheaths killed by the fungus are always pinkish-brown in color, while the rind, if the shoot has succeeded in producing any stick, is a deep bluish-gray. These colors are quite characteristic in canes afflicted with this disease and consequently are an aid to correct diagnosis.

Careful cultural studies of diseased tissues disclosed the fact that iliau was caused by a fungus previously unknown. It belongs to the genus Gnomonia, and was named Gnomonia ilian. The vegetative or feeding mechanism of this fungus consists of minute branching threads (mycelium) which grow through the cane tissues, destroying the living cells and absorbing their contents. The fungus produces two types of fruiting bodies, one in the form of pustules in the inner leaf-sheaths and stem (Fig. A), and the other in the form of tiny calabash-shaped bodies which are imbedded in the superficial leaf-sheaths with only their tips exposed (Fig. B). Enormous numbers of black spores (Fig. C)

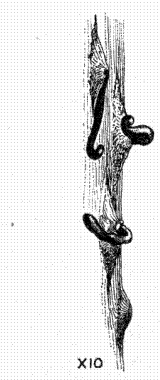

Fig. A. Melanconium iliau. The spore masses exuding through ruptures in the rind of a diseased stiek.

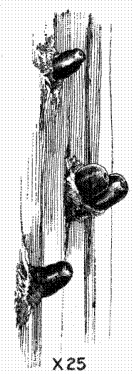

Fig. B. Gnomonia lliau. The tips of the fruiting bodies burst through the surface of the leaf sheath and appear as truncated cones slightly tilted up. ward. 


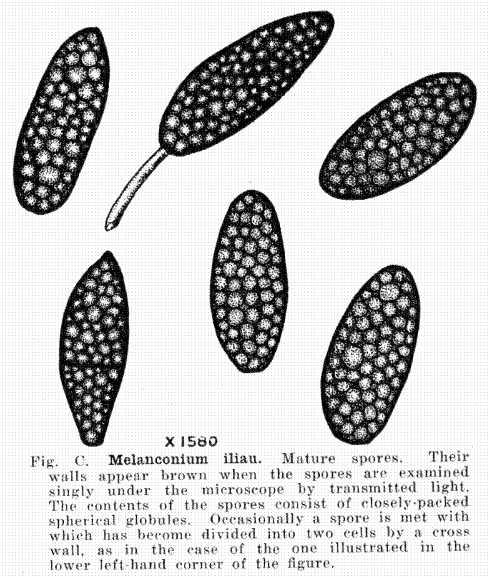

are forced out of the pustules, while many smaller, colorless spores are produced in little sacks within the calabash-shaped body (Figs. D and E). All of these spores are capable of reproducing the fungus, the large black spores being adapted to dispersal by water, and the smaller, colorless spores to dispersal by air currents. The fungus mycelium arising from the spores usually becomes established in the soil, living on decaying vegetable matter, and from this point invades the tisstes of the cane plant whenever opportunity offers. The spores and mycelium of this Gnomonia are very sensitive to sunlight, a brief exposure to the direct rays of the sun being sufficient to kill them. This fact is taken advantage of in our methods of controlling the disease.

lliau is in reality a leaf-sheath disease, and the methods of attack employed by the fungus make it a disease of young shoots only. As a rule, this fungus gains entrance to the tissues of a cane shoot by forcing its way into the leaf-bases which join the stem at a point below the surface of the soil. Once inside the tissues, however, it works its way upward and inward, progressing from leaf-sheath to leaf-sheath and eventually into the stem. Having gained entrance to a leaf-sheath, it usually travels rap- 
idly upward in its tissues and may extend through nearly the entire sheath before it has forced an entrance at any point to the next leaf-sheath within. A leaf whose sheath has become af-

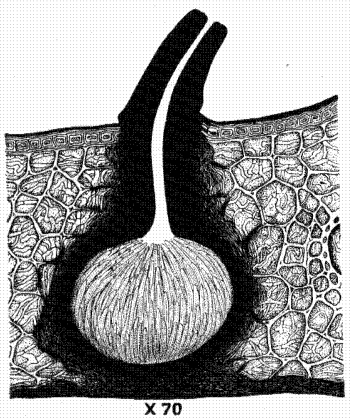

Fig. D. Gnomonia liau. A section through one of the fruiting bodies, showing its structure and association with the mycelinm in the tissue of the leaf sheath.

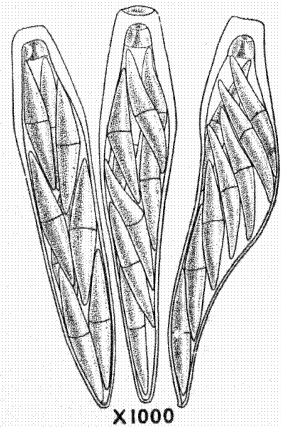

Fig. E. Gnomonia lliau. Three asct or spore-sacs from the interior of a fructification. Each aseus contains eight two-celled, spiudle-shaped spores. fected with the funguts soon dies as a result, but does not drop away from the stem, its sheath being cemented very securely to the leaf-sheaths within.

Thus the fungus works its way into the tightly-packed roll of leaf-sheaths which surround the young stem-tip, cementing these together into a rigid cone. The leatsheaths on a young shoot are naturally very firmly attached to the stem by their bases, and when the fungus cements them together over the tip of the stem this tender nember is securely confined within an inflexible $s \mathrm{t} r$ a ight jacket from which it cannot possibly escape. It usually dies long before the mycelium has reached it, because its natural growth and elongation are forcibly stopped. If one splits open young shoots which are well within the grasp of the disease, they often find 
that the stem has become varionsly bent and cloubled upon itself in striving to continue its elongation.

It very often happens, when a young shoot is attacked by the fungus, that the rapid elongation of the stem will carry its apex through the danger zone before the mycelium has progressed upward and inward sufficiently far to cement the leaf-sheaths together above it and head it off. In such cases the operations of the fungus are confined to a few leaf-sheaths, and may perhaps scar the stem slightly at one or two nodes, but the shoot will pass through the disease without suffering any considerable harm. Sticks which have thrown off the disease in this manner are very numerous in our cane fields.

There are also infrequent cases where shoots have recovered from ilian, although at one time in a very serious plight (Page 44, Fig. 2). Such sticks always have one or more joints near their base which are badly shriveled and blackened. These joints are always weak and brittle, and the stick is very liable to break off here as it increases in length and weight.

Iliau is a disease which thrives to best advantage during cool, damp weather. In fact, it is only under these conditions that it can make any appreciable headway. It is most abundant, therefore, where these conditions most frequently obtain. In the fields of low elevation on the southerly slopes of the mountains fatal cases are of infrecuent occurrence. A very destructive epidemic occurred, however, in such a field at 400 feet elevation during the winter months of 1910-11. In all fields at high elevations well-marked cases of iliau can usually be found at any season of the year, and this is more or less true of most low-lying fields having a northern exposure.

Iliau is therefore always present in, or at least not far removed from, every cane field in the Islands. If, while a field is carrying young cane, a period of cool, damp weather occurs, the disease is sure to make its presence apparent. Its spread through the fields, as well as the severity of the individual cases, will depend upon the continuation of the cool weather. With the return of warm weather, favorable to the growth of the cane, the disease is checked and many of the shoots only recently attacked will grow away from it. Severe epidemics of iliau are most frequent, therefore, in those localities where one or more months of continuously cool weather are of yearly occurrence.

As a general rule, it can be said that any shoot which shows a well-marked case of iliau is not worth saving by artificial treatment. All practical methods of combatting this disease must be in the nature of preventive measures rather than cures. 


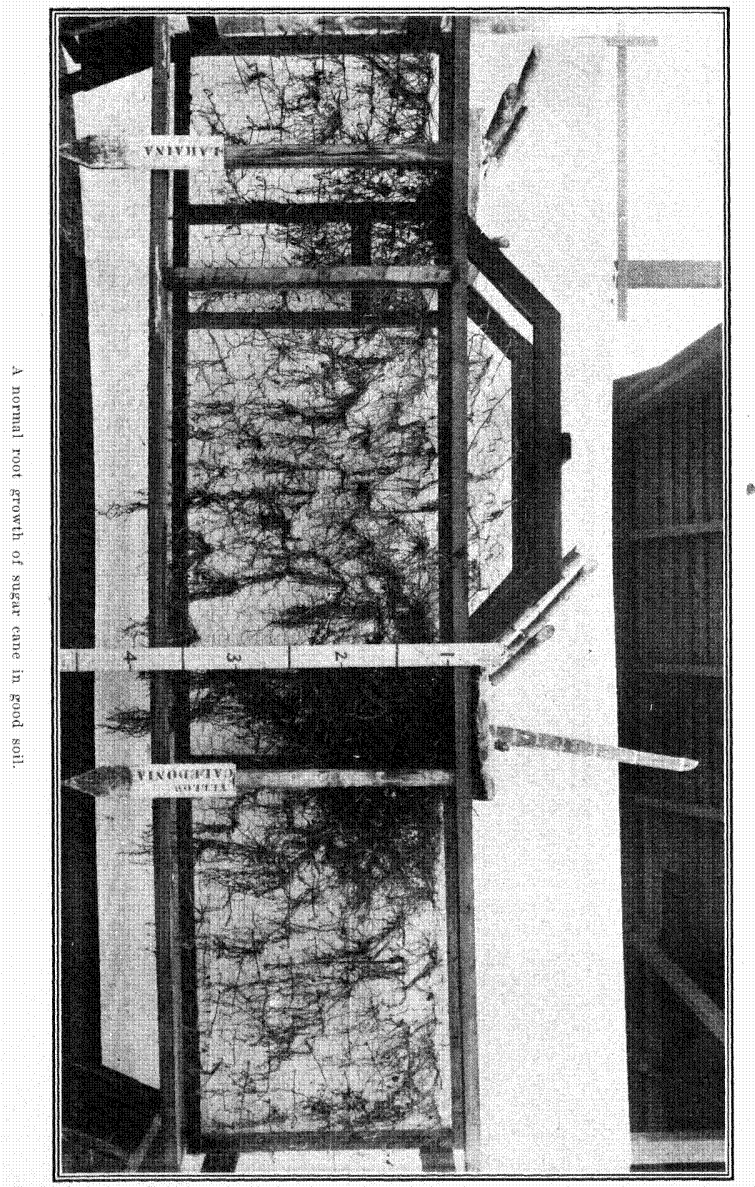


Thorough preparation of the soil previous to planting is a very efficient measure against iliau. After a crop of cane has been harvested the soil is certain to be well filled with the mycelium and spores of the iliau fungus. Such of these as are permitted to remain continuously buried until the next crop has started will undoubtedly retain their vitality and serve to infect the plant cane whenever the weather conditions become favorable. Such spores and mycelium as are brought to the surface and exposed to the sun for only a few hours, however, are effectually destroyed and can cause no further trouble. The more times the soil is worked over, therefore, the larger will be the percentage of spores which are brought to the surface and killed by being exposed to the sun.

Another practice which yields good results as a precaution against iliau is early planting of all fields liable to become severely affected. The result aimed at is to secure a good stand of cane as far along as possible before cold, damp weather sets in. As long as the cane shoots remain clothed in a series of closely-clasping, succulent leaf bases which extend lown into the ground, they are liable to fall prey to iliau if the necessary conditions for infection obtain. If the cane can pass through this critical period during warm weather it is fairly safe from the disease.

The investigation of this disease disclosed the characters and habits of the responsible fungus, and our preventive measures are based on this knowledge.

PRECAUTIONS AGAINST EPIDEMICS.

There is no way of knowing just when some new disease is going to appear in epidemic form in our fields, but there are certain precautions which we may take to protect our crops. To have an epidemic disease among our plants, an aggressive parasitic organism capable of causing the disease must be at hand. Such an organism may arise locally or it may be imported from some other country.

Any incipient parasitic organism attacking a plant may at any time acquire such virulence as to render it eapable of causing a destructive epidemic. (Or a parasite may suddenly take to a new host plant with disastrous results for that plant. The coffee leaf disease, caused by a parasitic fungus, was first observed on a single estate in the hilly country of Ceylon. It spread, however, with incredible rapidity and soon had extended its ravages throughout India, China, the Malay Peninsula, and every island 
in the Orient where coffee was grown.* The fungus causing this disease proved to be one that had previously occurred only on the leaves of a wild plant common in the forests of Ceylon and India. It is evident that some unknown influence acting on certain individuals of the original race of fungi taught them to live on the coffee plant. From this source there sprang a race which by choice lived entirely on the leaves of the coffee.

We recognize, therefore, that parasitic organisms, and even saprophytic organisms, may so change their habits as to suddenly render them dangerous enemies to our cane. To insure our crops against such an event we are acquiring an accurate knowledge of the habits and life-histories of all organisms to be found growing in intimate relation to the sugar cane or allied plants in Hawaii. Then if one of them should at any time become dangerous we shall know the most vulnerable point in its life-cycle and the best methods of combating its spread.

For most cultivated crops there are now extant many organisms capable of producing epiclemic diseases. These organisms are usually confined to certain countries by geographical barriers. It can be safely stated that, should one of these organisms be introduced into any country where its host plant is being cultivated, a serious epidemic is almost certain to follow.

The first and most effective protection against the importation of disease-producing organisms is a strict plant quarantine. The second line of defense is perfected by obtaining a thorough knowledge of the disease to which our crops are subject in other countries. Then if one of these diseases appears, knowing its symptoms and cause, we shall be able to recognize it at once. The prompt institution of adequate defensive measures will eraclicate any disease if it is discovered in time. To make our defensive measures adequate we must know the habits of the organism causing the disease.

The Hawaiian sugar planters fully recognize the dangers lurking in other sugar-growing countries and support a very strict quarantine. They have taken out further insurance by sending their pathologists to Fiji, Australia, Java and the Philippines to study the cane diseases of those countries. This latter procedure has placed at their disposal a knowledge of several very dangerous cane diseases concerning which nothing had ever been published.

When a very serious fungus disease broke out in epidemic form in the cane fields of Formosa we already knew the symptoms and cause of the malady, and the source from which they

* It is estimated that this disease caused a loss to the colony of Ceylon alone of over $\$ 5,000,000$ per annum for several years. 


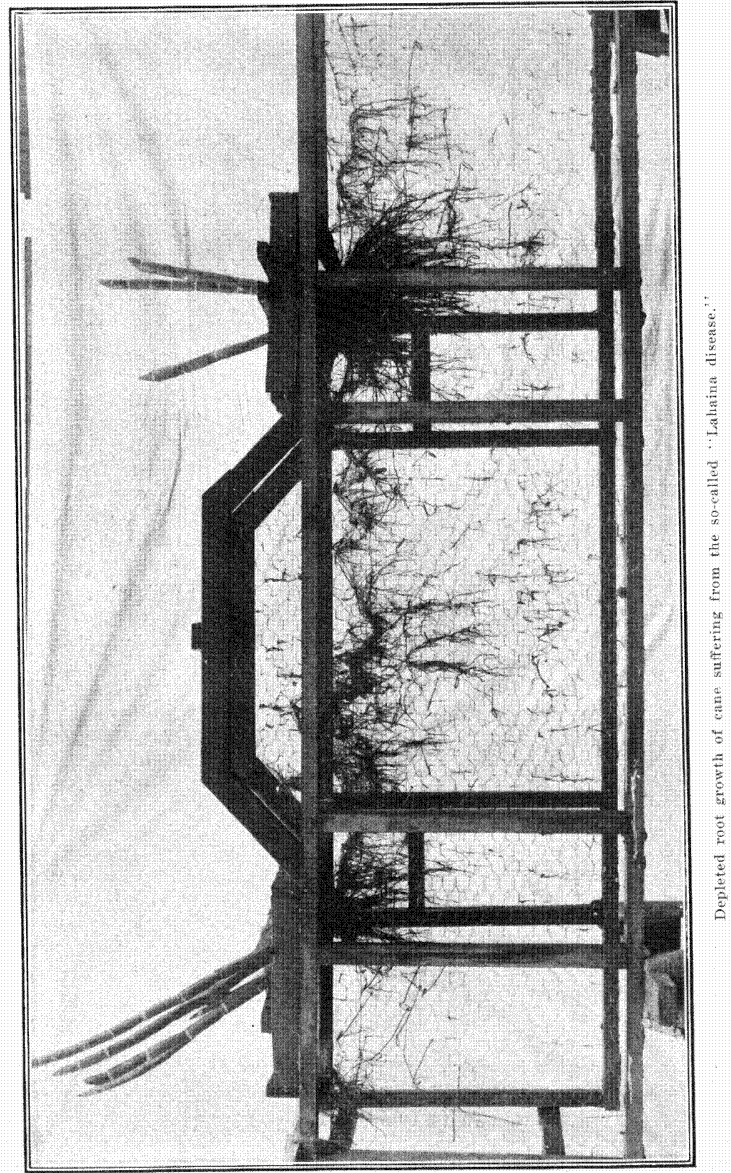


had imported it. In Formosa they did not become aware of the nature of the disease until it had gotten beyond their control. There is not much langer of the Hawaiian sugar planters having a similar experience with this or any other of the numerous cane diseases known to occur in the sugar-growing countries around the Pacific.

\section{MANUFACTURE.}

By R. S. Norris.

The so-called manufacture of raw' cane sugar consists, in the simplest terms, of the recovery, in the form of small crystals, of the sugar which is in solution in the cane juice. This recovery involves, in general terms, the extraction of the juice from the cane by pressing, the elimination of those constituents of the juice that can be precipitated by heat and chemicals, the evaporation of as much of the water as is necessary to allow the maximum quantity of sucrose to crystallize out, and the separation of the sucrose crystals from the mother liquor.

In this process of recovery it is the constant endeavor of the Hawaiian plantations to make use of the very best machinery and methods that are known. For the purpose of increasing the efficiency and economy of manufacture there is constantly being tried out on our plantations new processes and new forms of machinery invented here and in other cane sugar countries. It is in this way that Hawaii has earned the reputation of being in the lead over all other cane sugar countries in the manufacture of sugar as well as the growing of cane. A few quotations from authorities on this subject will bear me out in this statement. H. C. Prinsen Geerligs, the well-known authority of Holland and Java, in his book, "The World's Cane Sugar Industry," says: "The manufacture of sugar from sugar cane in the Hawaiian Islands is carried on in the very best possibe way. * * * Their factories are installed with the best machinery to be had.",

Professor Geo. T. Surface of Yale University, in his treatise on the world's sugar industry, "The Story of Sugar," says: "Hawaii leads the cane-growing world in the mechanical facilities of her mills."

Mr. Noël Deerr, the English cane sugar expert, formerly technologist at this Station, in his report to the Secretary of Agricul- 
ture of Cuba on the sugar industry of that island, uses the expression: "In the highly efficient and highly organized industry in Hawaii," in comparing the industry in that country and in this.

In order to show how Hawaii compares with other cane sugar countries in the machinery equipment of its factories, and how rapidly new machinery and methods are adopted after they have been demonstrated to be improvements over the old forms, I will review the different divisions of the manufacture.

It was demonstrated on these Islands that the highest results in the extraction of the juice from the cane cannot be obtained with less than four three-roller mills in the train. It is interesting to see how fast the use of the longer trains of mills spread after their increased efficiency had been proven. The following shows the percentage of the different kinds of mills in use during a period of six years:

\begin{tabular}{|c|c|c|c|c|c|}
\hline No, of 3 -roller mills. & 1910 & 1911 & 1912 & 1913 & 1914 \\
\hline Four or more........ 11 & 17 & 20 & 22 & 32 & 42 \\
\hline Three . . .... & 68 & 65 & 63 & 55 & 47 \\
\hline Less than three.. & 15 & 15 & 15 & 13 & 11 \\
\hline
\end{tabular}

Cane mills with four or more three-roller mills were in use in Hawaii for several years before any other cane sugar country adopted them. Prinsen Geerligs, in his book mentioned above. referring to the work of the cane mills in Hawaii, says: "The extraction results thus arrived at are never met with elsewhere."

Java probably stands next to Hawaii in the high efficiency of her cane sugar factories. A comparison of the average results obtained by all the cane mills of each country, in extracting the juice from the cane, shows that Hawaii is far in the lead. The results in the table are expressed in percentages of the sugar in cane obtained in the juice, ordinarily called "extraction."

\begin{tabular}{|c|c|c|c|}
\hline & & -Average & Extraction - \\
\hline $\begin{array}{l}\text { Year. } \\
1910\end{array}$ & & $\begin{array}{c}\text { In Java. } \\
91.2\end{array}$ & $\begin{array}{c}\text { In Hawaii. } \\
93.63\end{array}$ \\
\hline 1911 & & $9(0.6$ & 93.54 \\
\hline 1912 & . & 90.8 & 93.89 \\
\hline 1913 & & 90.7 & 94.25 \\
\hline 1914 & & 90.4 & 95.46 \\
\hline
\end{tabular}

Analogous figures for Cuba are not available, but from results which we have from a few of the leading plantations, we are 


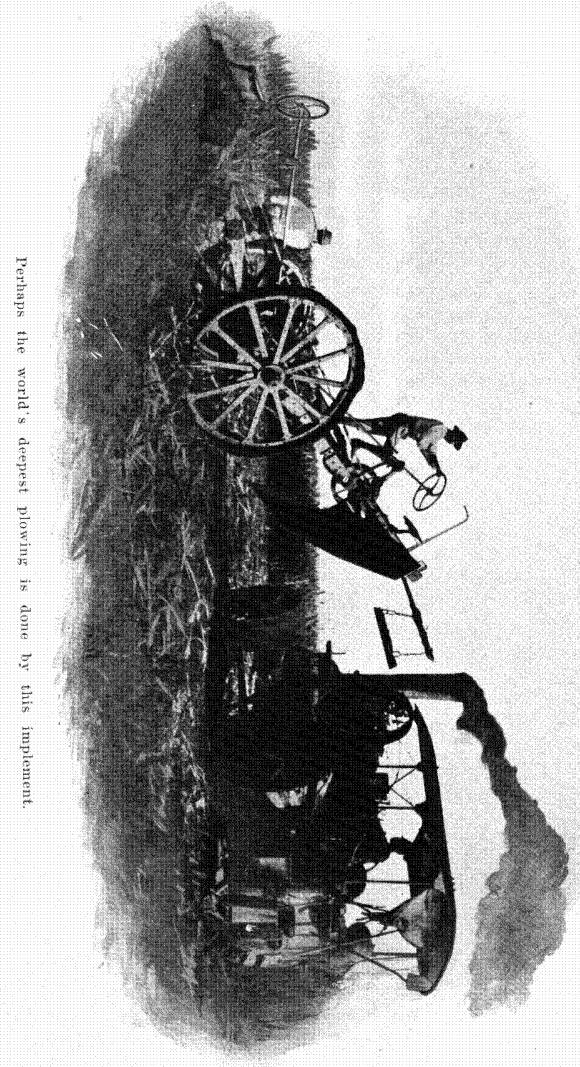


quite positive that the average extraction there is no better than in Java. Results from six of these plantations for the season of 1914 show an average extraction of 91 , the maximum being 93.5. The maximum in Hawaii runs over 98. This means that from the amount of cane that is anually ground in Hawaii the output of sugar is about 25,000 tons greater than would be obtained by the quality of milling that is done in Java or Cuba.

As a further example of the rapidity with which new icleas in methods and machinery of proven value are aclopted, I would refer to the case of a new method of grooving mill rollers invented by one of our factory superintendents. By grooving the rollers in this way it was found that a materially increased extraction could be obtained. The Messchaert deep juice-grooves were first tried at the beginning of the season of 1914. There are now in use 116 rollers grooved in this manner, in thirty of the forty-five mills in operation.

Mr. Noël Deerr, in the Cuban report referred to above, makes the following statements in comparing the milling in the two countries: "The quality of mill work in general in Cuba does not reach the high standard to which the writer has been accustomed to in his Hawaiian experiences." "During the last few years the efforts in Hawaii to obtain efficiency at the milling plant have been attended with great success, and for the crop just finished the average extraction there is of the order of 95 per cent; that is to say, the mills have extracted 95 per cent of the sugar in the cane. I have no complete statistics of the work in (uban mills, but of twenty returns to which I have hat access, only two reached as high as 94 per cent. If these twenty mills be taken as typical of the average, and they include some of the most recent as well as some of the older plants, I estimate the average extraction in Culban mills as 91-92 per cent."

()ther instances of this keenness for improvements in our factories may be cited. During the season of 1913 a new form of settling tank was tried in one factory and found successful. It is now in use in nine other factories. The most reliable and effective means of increasing the steam and fuel economy in sugar factories has been by increasing the number of cells in the evaporator. In most cane sugar districts the evaporators usually have two or three cells. In Hawaii only one factory has a twocell evaporator, and about fifty per cent of them use quadruple evaporators. Within the last few years nine factories have installed large quadruple effects of the "Standard" type, this having been proved to be the form best aciapted to our needs. Just before the beginning of the season of 1912 the Technologist of the Station called attention to the advantages to be derived by a 
further extension of the principle of multiple effect evaporation in the use of pre-heaters and pre-evaporators. In order to make use of these suggestions elaborate and quite expensive changes were generally necessary, but, nevertheless, pre-heaters or preevaporators are now employed in ten factories. In 1908 a new form of vacuum pan was installed in one of the factories, the usual copper coils being replaced with a calandria. It proved to be efficient and now sixteen factories are using twenty-one calandria pans.

The main activities of the Experiment Station on the manufacturing side of the industry are the inspection of the factories during the grinding season, advice and assistance in overcoming any special difficulties, investigations and reports on new processes of manufacture, compiling a weekly tabular report showing the restults obtained by each factory during that period, and an annual report giving the manufacturing results for the season and a discussion of them.

Every season the Technologist of the Station inspects the work of a large proportion of the factories in the Territory, and reports are sent to the managers and directors of the plantations with comments on the quality of the work and suggestions toward improvements. The Station is also called upon for special investigations of particular parts of the manufacture.

The opinion and advice of the Experiment Station is called for on any new processes that seem at all feasible. In this way it has several times saved the investment and loss of considerable amounts of money in proposed processes that contained technical fallacies which made them unworkable. The Station also recently carried out an experimental investigation on a manufacturing scale of an elaborate process covering a period of two years, for the Sugar Planters' Association.

Each week practically every factory in operation on the Islands sends to the Experiment Station a report showing the composition of the various products and the weights of materials handled. These figures are printed on a sheet in tabular form and distributed with as little delay as possible to the plantations. Particular care is taken to have the figures correct and to present the important ones in a striking form. This report is eagerly scanned on the plantations by those in charge of the factory operations, and it furnishes an incentive toward continually renewed efforts for improvement in the work in order to keep up to or increase their standard.

The annual report on manufacture gives the results obtained by each factory for the season. These results are cliscussed and the factories compared on the basis of them. It is probably re- 
ceived with greater interest on the plantations than any other publication, and has contributed materially, during the last few years, toward raising the standard of chemical control and of manufacture.

A few average figures from the annual reports will serve to show the quality of the work done in Hawaiian factories:

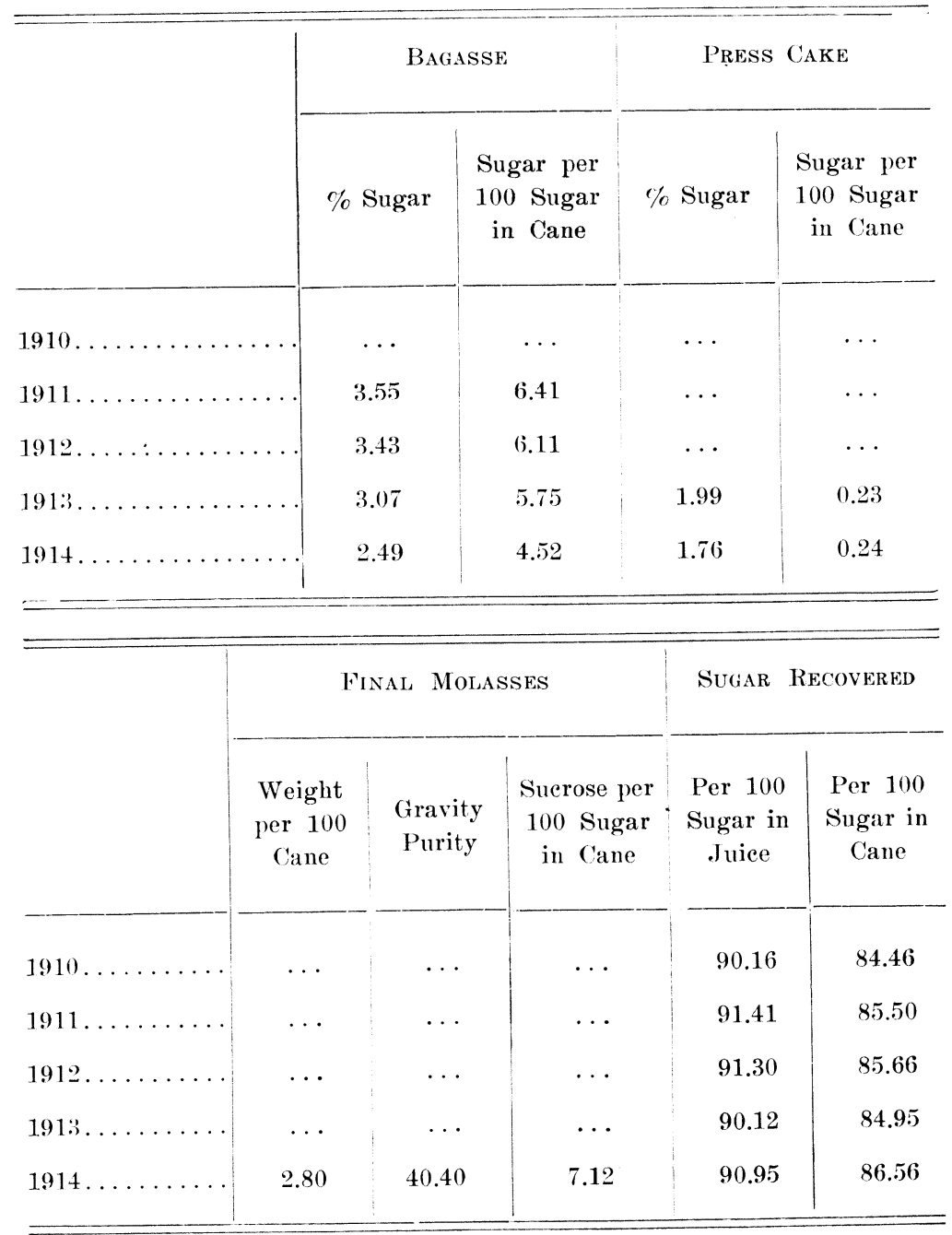


For the items that are left blank in this table no figures are available.

In the report the quality of the work of the different factories for the season is compared on the basis of the percentage of sugar recovered of that possible to recover. The recoverable sugar cannot be calculated accurately from the figures available, so that this comparison is only approximate, but it gives a general idea of the efficiency of the manufacture on the plantations. For the 1914 season the factory efficiencies stood as follows:

TOTAL RECOVERY.

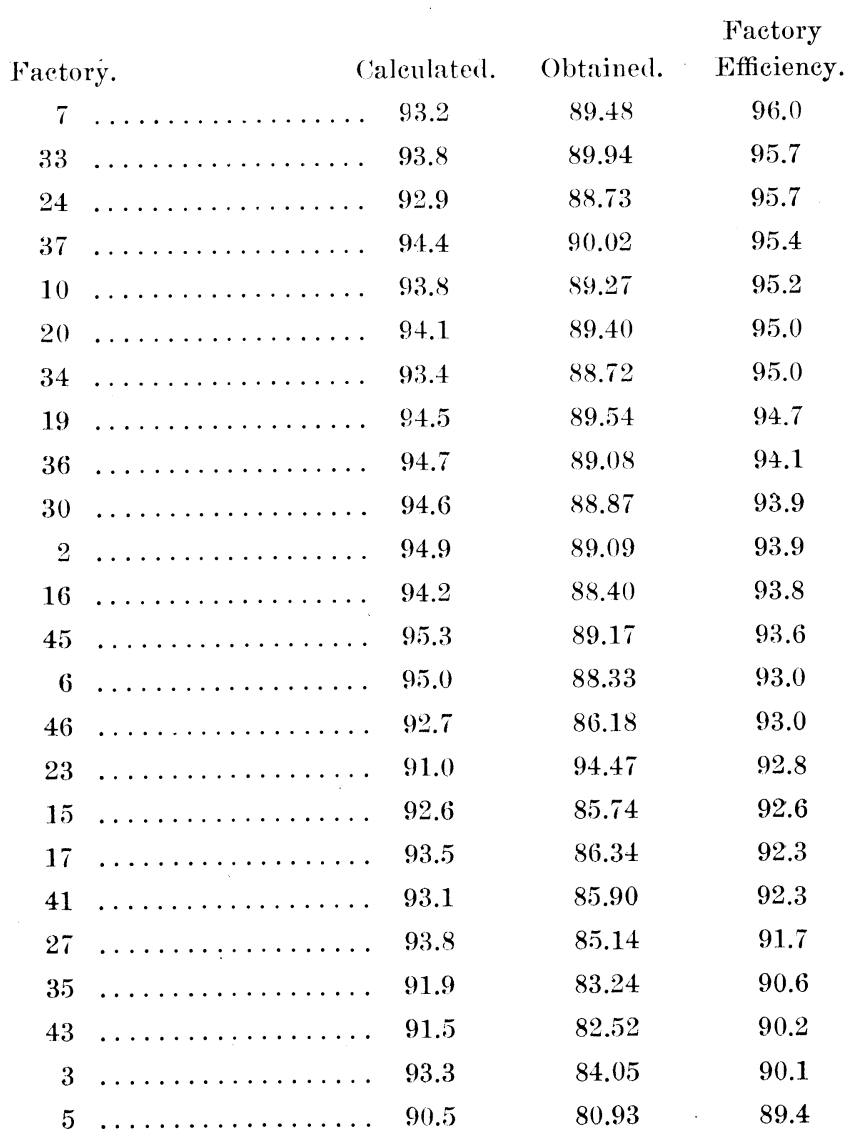




$\begin{array}{lllll}47 & \ldots \ldots \ldots \ldots \ldots \ldots \ldots & 92.0 & 82.26 & 89.4 \\ 25 & \ldots \ldots \ldots \ldots \ldots \ldots \ldots & 91.5 & 81.24 & 88.8 \\ 40 & \ldots \ldots \ldots \ldots \ldots \ldots \ldots & 93.7 & 83.16 & 88.8 \\ 38 & \ldots \ldots \ldots \ldots \ldots \ldots \ldots & 90.9 & 80.28 & 88.3 \\ 31 & \ldots \ldots \ldots \ldots \ldots \ldots \ldots & 95.0 & 83.44 & 87.8 \\ 42 & \ldots \ldots \ldots \ldots \ldots \ldots & 93.6 & 82.18 & 87.8 \\ 32 & \ldots \ldots \ldots \ldots \ldots \ldots \ldots & 93.7 & 82.26 & 87.8 \\ 12 & \ldots \ldots \ldots \ldots \ldots \ldots & 93.9 & 79.58 & 84.7\end{array}$

\section{CHEMISTRY.}

By P. S. Burgess.

When the Experiment Station of the Hawaiian Sugar Planters' Association was founded in 1895, the chief work of the Station for the first few years was largely of a chemical nature. Prior to the founding of this Station, which was the first agricultural experiment station to be instituted on these Islands, very little agricultural work of a scientific nature had been attempted here.

In 1882 Captain C. E. Dutton, employed by the U. S. Geological Survey, had spent a year on the Islands studying, more or less superficially, the geography, geology, people, plants and animals to be found. His report, covering 137 pages in the Annual Report of the U. S. Geological Survey for 1883, contained practically all that was scientifically known concerning the lavas and more especially the soils of the Hawaiian Islands up to 1895. The Sugar Planters' Station was thus a pioneer in the field of scientific agriculture on these Islands.

The work in chemistry quite naturally falls under three main heads or divisions: research work, fertilizer control work, and miscellaneous analytical work. These three divisions in the work were made early in the history of the Station, and for the sake of convenience have been quite closely adhered to up to the present time. We will now give a very brief resumé of the work done under these three heads. 
RESEARCH WORK.

The research work has been concerned largely with the physical, chemical and biological aspects of the soils of these Islands, although other projects intimately connected with the manufacture of sugar and the growing of cane have, from time to time, received attention.

The early work on Hawaii soils was of interest not only to the planters here, but also to soil scientists in other lands. Nowhere else do we find such a diversity of soil types, or such abnormal soil formations as are here encountered. The rocks composing the whole mass of the archipelago, with the exception of limestone and coral formations, are of comparatively recent volcanic origin, and may be collectively termed basaltic lavas. By disintegrating and weathering these lavas have given us soils of very different types from those commonly met with elsewhere. They are primarily basic in composition, whereas those of North America, for example, are acidic. The basis or framework of Hawaiian soils are the oxides of iron and aluminum, whereas the basis of mainland soils is silica. A glance at the following table will show these great differences better than words can express them. These figures represent averages of large numbers of soil analyses made by the "absolute" or "fusion" method. The column marked "Mainland Soils" represents averages of soil analyses from almost every State in the Union and from provinces in Canada. The column labelled "Hawaiian Soils" gives average figures for over 300 composite samples of soil from the leading types on all of these islands. All of these analyses were made here and under similar conditions.

\begin{tabular}{|c|c|c|}
\hline Basic constituents & $\begin{array}{l}\text { wailan Soils. } \\
\text { Per Cent. } \\
\quad 63.717\end{array}$ & $\begin{array}{c}\text { Mainland Soils. } \\
\text { Per Cent. } \\
18.980\end{array}$ \\
\hline Acirlic constituents . & 36.458 & 81.014 \\
\hline $\mathrm{Fe}_{2} \mathrm{O}_{3}+\mathrm{A}_{1} \mathrm{O}_{3} \ldots \ldots \ldots \ldots$ & 59.240 & 13.250 \\
\hline $\mathrm{CaO} \ldots \ldots \ldots \ldots \ldots \ldots \ldots$ & 0.698 & 0.830 \\
\hline $\mathrm{MgO}$ & 1.242 & 0.771 \\
\hline $\mathrm{K}_{2} \mathrm{O}$ & 0.737 & 1.622 \\
\hline $\mathrm{Na}_{2} \mathrm{O} \ldots \ldots \ldots$ & 1.420 & 2.229 \\
\hline
\end{tabular}

The table below shows differences in the soils from the two areas as brought out on analysis by the "agricultural method" (hot digestion 10 hours in hydrochloric acid, sp. gr. 1.115). The figures here also represent averages of many determinations. 
Hawaiian Soils. Mainland Soils.

Per cent.

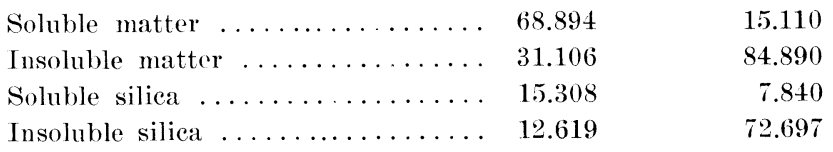

It is of interest to state here that analyses of German soils were obtained from Professor Maercher, and of English soils from Professor Lawes. Averages of these compared fairly closely with those of American soils.

The above data require little comment. It shows that the cardinal difference lies in the relative contents of iron and alumina and of silica.

Physically, as would be expected, the soils differ greatly among themselves and also from American soils. The average specific gravity of Hawaiian soils is 2.87 as compared with about 2.6 for American soils. The specific gravity of the former, free from combustible matter, is approximately 3.4.

The soils of the Islands are, for convenience, classified or divided into two large groups, the "makai" or low-lying soils, and the "mauka" or upland soils. The mauka lands, at an elevation usually of 500 feet and above, receive by far the heaviest rainfall. Their nitrogen content is thus about three times that of the low-lying makai lands nearer the sea. The following table gives the average chemical composition of these two soil groups, and represents averages of determinations on soils from all the islands :

\begin{tabular}{|c|c|c|}
\hline $\begin{array}{l}\text { Plant Food Element. } \\
\qquad \mathrm{CaO} \ldots \ldots \ldots \ldots\end{array}$ & $\begin{array}{l}\text { Makai Soils. } \\
\text { Per Cent. } \\
\text {. } 0.474\end{array}$ & $\begin{array}{c}\text { Mauka Soils. } \\
\text { Per Cent. } \\
0.268\end{array}$ \\
\hline $\mathrm{K}_{2} \mathrm{O} \quad$ & . $\quad 0.328$ & 0.332 \\
\hline $\mathrm{P}_{2} \mathrm{O}_{7}$ & 0.213 & 0.238 \\
\hline $\mathrm{N}$. & 0.176 & 0.401 \\
\hline
\end{tabular}

The makai soils are largely sedimentary soils which have been brought down from the mountains by streams and otherwise, and are sometimes mixed with considerable quantities of coral. These soils are as a rule much richer and deeper than the mauka soils, and usually produce larger crops.

Due to the preponderance of iron and aluminum, the phosphoric acid in Hawaiian soils is in large part locked up so se- 


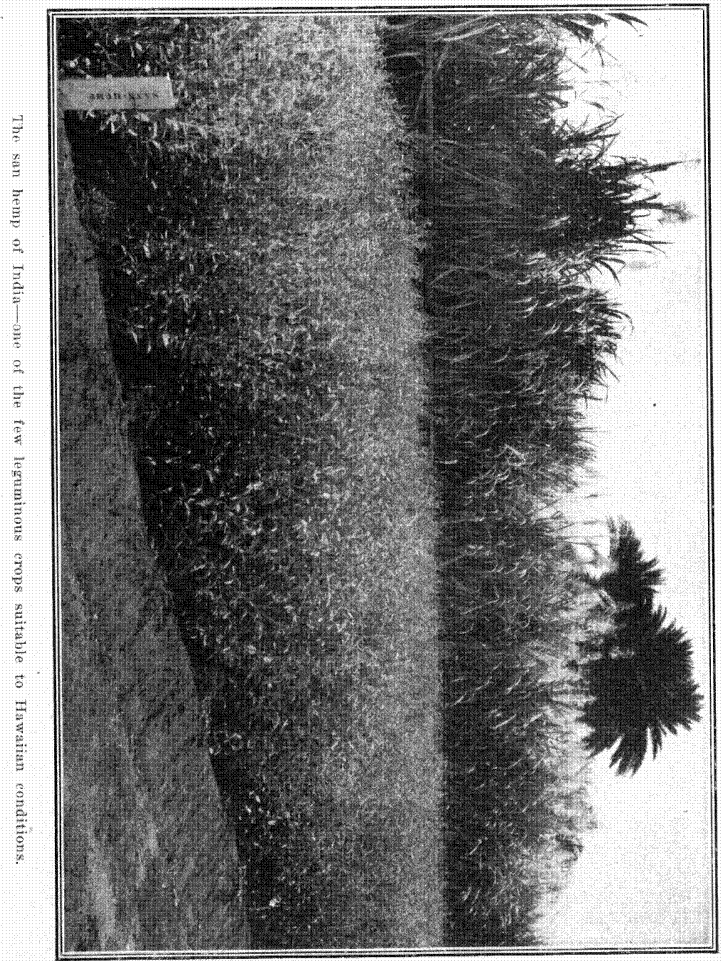


curely that plants can use it with lifficulty. Some soils, containing over 12,000 pounds $P_{2}()_{5}$, per acre-foot, give less than twenty pounds in an immediately available form.

The nitrogen also in most of our soils, although present in large amounts, has been found to be very resistant to rapid nitrification, and thus exists largely in unavailable forms.

Potash, as it exists in Hawaiian soils, is present in a fairly available state. The same may be said of lime.

Besides the large amount of laboratory work which has been done on soils brought directly from the field, many lysimeter and tub experiments have been conducted, both cropped with cane and fallowed. These tests have been made with the following objects in view: to note the effect on the growth of cane of applications of fresh and salt irrigation waters; to letermine the transpiration coefficients of cane at different stages of growth and the amounts of water required to produce cane of different varieties (pounds of water per pound of sugar); to determine the rates of nitrification of different forms of organic nitrogen in soils; to determine the effect of various forms of lime and of the fertilizer salts on nitrification in mauka and makai soils; to determine the effect of molasses, as a fertilizer, on nitrification.

Much chemical work has further been completed on the composition of the different varieties of cane and the amounts of plant foods which these different varieties withdraw from the soil per crop, and per ton of sugar produced.

Since irrigation is of prime importance in many localities on these Islands, much chemical work has been done on the natural and well waters, both as regards their "alkali content" and also for dissolved plant foods present.

Reference was made above to certain other fields of chemical research somewhat removed from soil and plant work. A lengthy and complete study was recently made on the composition of evaporator scale which was found to be largely sulphate and phosphate of calcium. Boiling with a dilute solution of sodium carbonate for the sulphate scale, and $1 / 4 \%$ to $1 \%$ hydrochloric acid for phosphate scale, was recommencled as a means of their removal. The manufacture of alcohol from waste molasses was also thoroughly studied. Eight varieties of yeast from as many parts of the world were carefully tried out as to their respective fermentation efficiencies.

About seven years ago I ahaina cane, which, by the way, is not a hardy variety, being especially susceptible to any slight adverse condition, began to show signs of deterioration on some of these islands. The plant pathologists and entomologists have as yet been unable to associate any disease or parasite which might 
cause this stunted condition. The Chemical Division is at present engaged in making a thorough study of the soils from these affected areas, with the hope of solving this most perplexing problem.

\section{FERTILIZER CONTROL WORK.}

Hawaii is a land of heavy fertilization. The annual fertilizer bill of these Islands amounts to more than $\$ 3,000,000$. These fertilizers are purchased by the plantations or their agents from

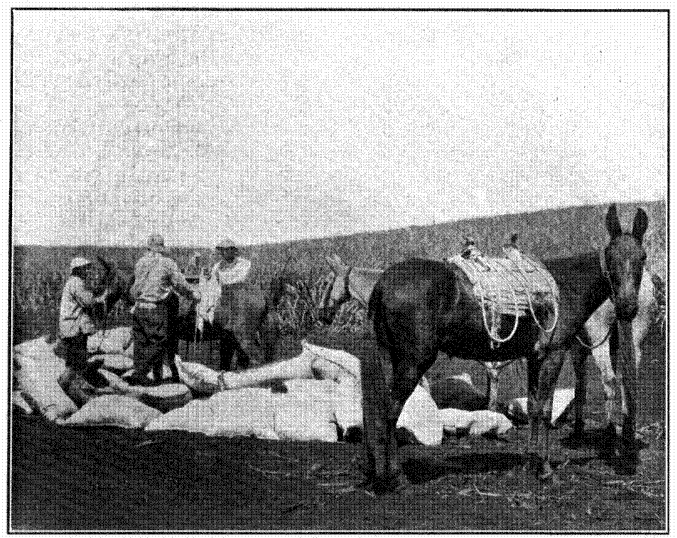

The ase of chemieal fertilizers is a highly developed part of sugar cane agriculture in Hawail.

both local and mainland manufacturers. The objects of our chenical control work are as follows:

1. To take official samples of fertilizers (particularly mixed fertilizers) purchased by the plantations of the H. S. P. A.

2. To obtain from the plantations or their agents a copy of the guaranteed composition of these fertilizers.

3. To analyze the samples, sending copies of their analyses to the plantations or their agents.

4. In case the fertilizers are below the guarantee to accom- 
pany the analysis reports with an estimate of the amount of rebate due the purchasers, as calculated from official valuations founded on market prices.

The Pacific Coast fertilizer shipments are sampled at San Francisco; the inter-island shipments are sampled in Honolulu. Each tenth bag of a consignment is sampled and from the sample so obtained the two bottles are filled; one being brought to the Experiment Station and the other to the plantation agency to be held in reserve in case the former sample should show a deficiency. After receiving the samples, the Experiment Station sends out printed forms to the plantation agencies, who fill in the guarantees of the fertilizers in question and return them. Our agent in San Francisco carries out the sampling in the same way, the samples being forwarded to the Experiment Station and to the plantation agencies once each month. All analyses are made in the chemical laboratories of the H. S. P. A. Experiment Station, in Honolulu, by the adopted official methods for fertilizer analysis. The following is a resume of this work for the past nineteen years:

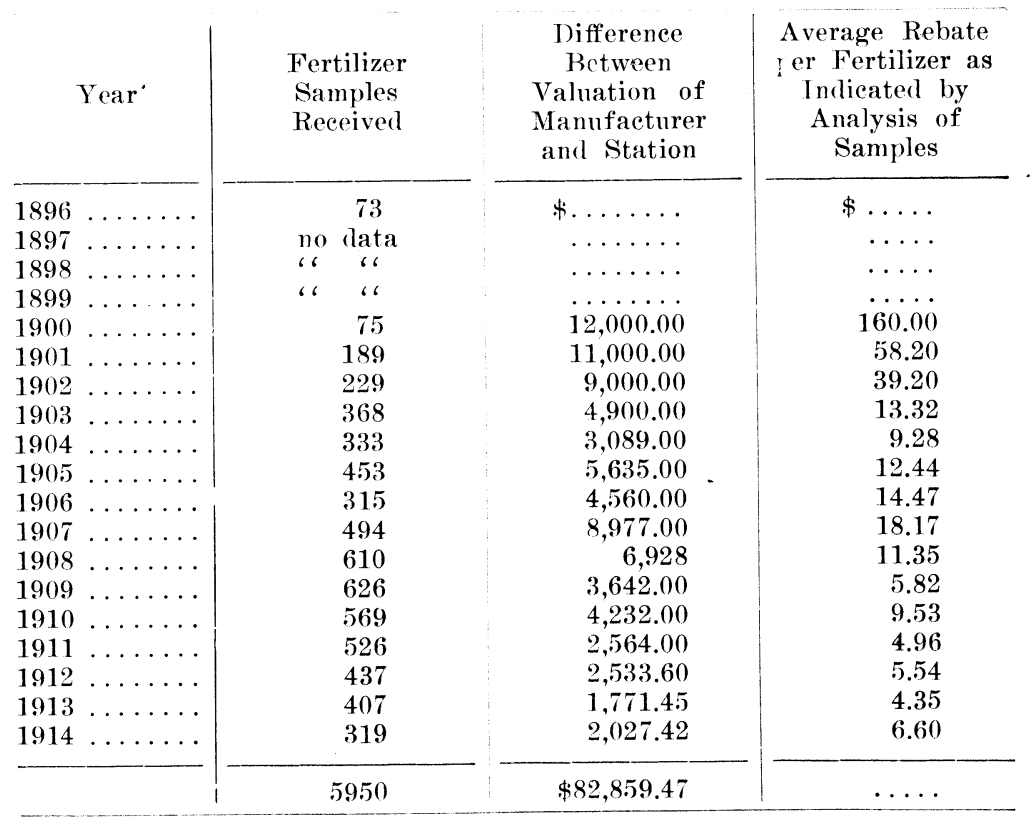




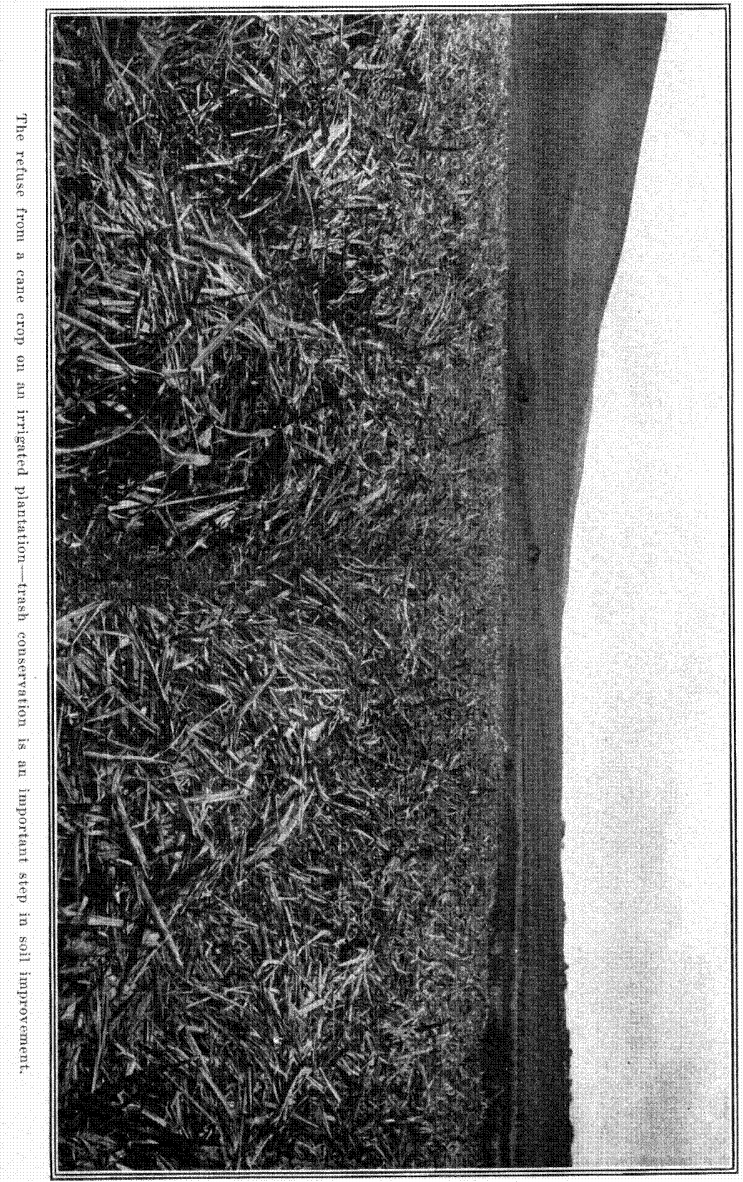


The above figures show that during the last fifteen years 5950 fertilizers have been analyzed with a total indicated rebate to the plantations of over $\$ \$ 0,000.00$, or about $\$ 5510.00$ per year.

MISCELLANEOUS ANALYTICAL WORK.

The plantations belonging to the Hawaiian Sugar Planters' Association send to this laboratory samples of all kinds whose chemical composition is desired. The analyses are made and the results submitted as soon as is compatible with accurate work. Among these miscellaneous samples the following predominate: molasses, sugars, cane juices, limestone, coral sand, lubricating and fuel oils, coal and ashes. On an average, about twenty miscellaneous samples per month are received and analyzed.

The work of the chemical division is carried on by the chief chemist, who is also responsible for the research projects; two fertilizer chemists; one analyst, whose time is well taken up with the miscellaneous samples, and three laboratory assistants. Changes are occasionally made, depending on the work. 


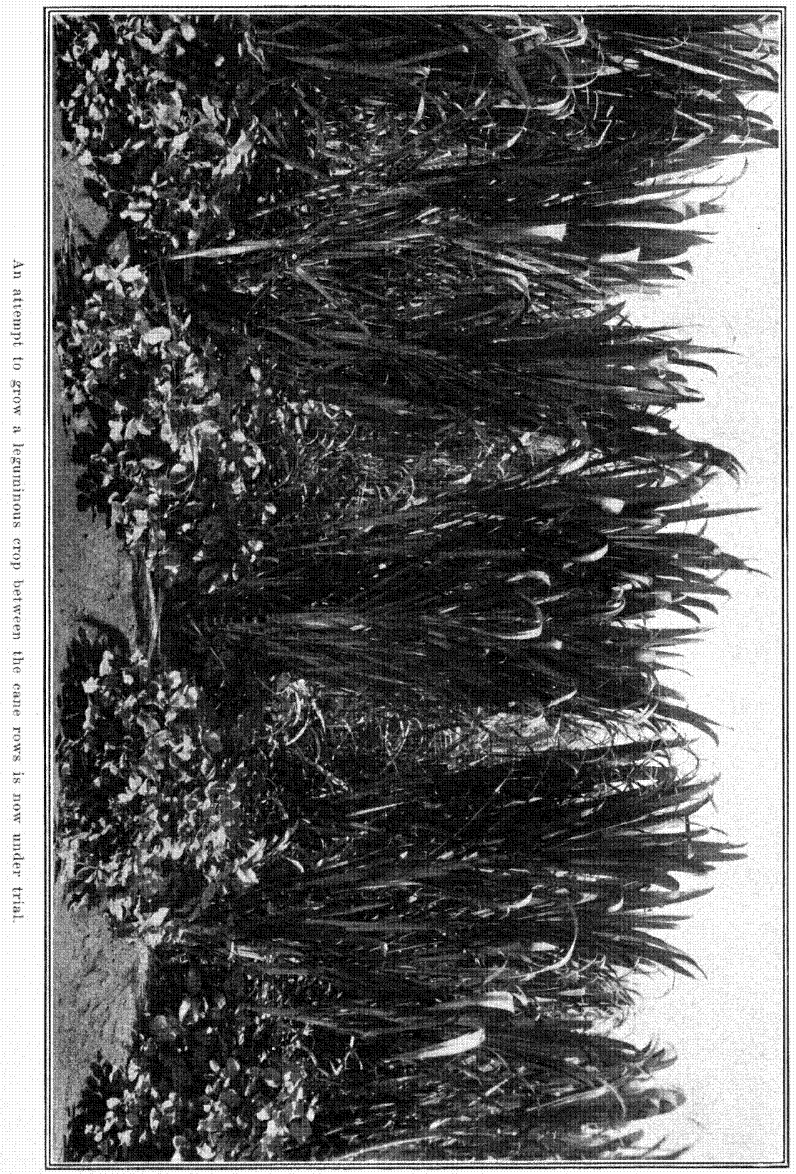




\title{
AGRICULTURE.
}

\author{
CANE VARIETIES.
}

With the adoption of rigid quarantine measures against the possibility of introducing injurious insects and plant diseases from foreign countries, it became necessary to forego the opportunity of bringing in superior cane varieties from other canegrowing localities. Prior to this time several excellent canes had been introduced. One of them, the Demerara 1135, has gained considerable popularity, and its area is being rapidly extended.

The local propagation of new seedling varieties was then resorted to as a relief from this situation. Sugar cane seedlings are in the vast majority of instances greatly inferior to the parent plants, and it is only by propagating them by the thousands and gradually weeding out the poorer ones that canes of commercial promise can be obtained. The following list gives the number of seedlings that have been propagated by the Experiment Station:

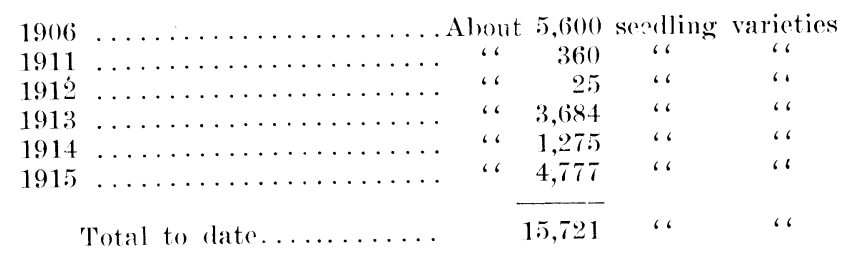

The relation of this work to the plantations may be judged from a report prepared in 1913 on the question of varieties, from which we quote as follows:

In recent years the Hawaiian plantations have devoted their attention prineipally to three varieties of sligar cane-the Rose Bamboo, the Lahaina, and the Yellow Caledonia.

Today Rose Bamboo has been largely dropped, less area is being devoted to Lahaina than formerly, greater acreages are planted to Yellow Caledonia than at any time since its aplearance in the fslands, and there are a number of new varieties that are being tested and in sone instances gradually extended.

It is more especially the purpose of this report to show the extent to which these new varieties are encroachig upon the so-called Standard ('anes. No attempt is marle to point out the comparative merits of the different varieties-comparative areas is the point under consideration.

We find that in all there are about 145 different kinds of cane being grown on the plantations of the IIawaiian Sugar Planters' Association, and that of these there are 42 varieties grown commercially, concedin's that when an area of one acre or more is devoted to a cane it assumes 
a certain commercial significance. On this basis Hawaii has 19 com mercial varieties, Kauai 6, Maui 9, and Oahu 33.

In point of area Yellow Caledonia is more extensively cultivated than any other variety, it being credited with over 116,000 acres for the 1914 and 1915 crops, against about 75,000 acres for Lahaina.

From the crop of 1913 to that of 1915 , Yellow Caledonia has a slightly increased area, while Lahaina shows a decline of about 5000 acres. On each of the four islands, there is a reported decrease in Lahaina. On Oahu this amounts to nearly 4000 acres. A decrease in Yellow Caledonia is shown on Hawaii; while the other three islands show increases in this variety, Oahu reporting a gain of about 2200 acres. We have no means of gauging the extent to which the reported declines will be made up from short ratoons in 1915 now classified as 1914 acres, and the figures should be accepted with this in view. 1

The next most important variety is $\mathrm{D} 1135$, to which 2709 acres have been planted for the 1915 crop. Striped Tip shows 2660 acres, but this is a decline from 3740 in the 1913 erop, while D 1135 increases from 829 acres, a gain of over 800 acres.

Whereas Lahaina is reported from 25 plantations, and Yellow Caledonia from 38 , there are 41 plantations growing $D 1135$ either commercially or experimentally. Of these 41 there are 29 which have an area of one acre or more of this promising Demerara seedling; there are nine plantations with areas of over a hundred acres each; there are three plantations with over 500 acres, and one of these has over 1000 acres.

Another interesting point about the D 1135 is that it is more evenly distributed throughout the four islands than any other variety. For the 1914 and 1915 crops, Oahu leads with 1569 acres, Hawaii follows with 1178, while Maui and Kauai report 963 and 484 acres respectively, making 4194 aeres now under cultivation.

Aside from the varieties thus far mentioned there are but two others which occupy areas of over 1000 acres-D 117 and Yellow Bambaa. It is significant to note that of the seven varieties of cane which occupy areas of over one thousand acres there are only three which show welidefined extension between the 1913 and 1915 crops-Yellow (aledonia, D 1135 and D 117.2 Lahaina, Rose Bamboo and Striped Tip all show decreased areas.

On the other hand there are about thirteen new varieties which, though eultivated as yet on a comparatively small scale, have been extended to an appreciable extent since the 1913 crop began. This fact makes these canes stand out prominently among the large number which have been undergoing preliminary tests for several years. They are listed as follows:

\footnotetext{
${ }^{1}$ Our present figures show 3001 acres less for the total area of the 1915 crop than for the crop of 1913 .

2 There is doubt regarding Yellow Bamboo. It is confined mostly to one plantation of which the 1915 acres are uncertain.
} 


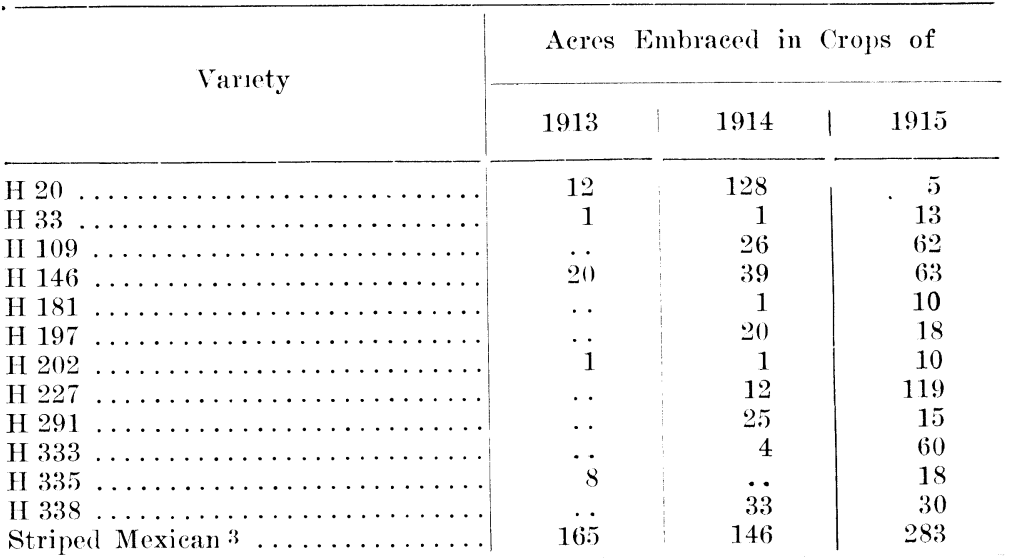

Since all the other varieties in the Islands had from several to many years' start on the Hawaiian seedlings, it may be well to see what is being done with those canes which have survived a long series of testing begun with some five thousand germinations secured about the year 1905. In approximately six years' time these have been reduced to 120 , and 26 of them have proved snfficiently promising to be cultivated today in blocks extending from one acre upwards.

To these twenty-six Hawaiian seedlings the H. S. P. A. plantations are now devoting 822 acres for the 1914 and 1915 crops. lisy far the greater portion of this is on the Island of Oahu, which contributes 699 acres or $85 \%$ of the whole amount. Hawaii furnishes 103 acres and Kauai 18 acres, while Mani reports but 2 acres.

Looking more closely into these figures we find that Ewa Plantation has a greater area in Hawaiian seedlings than all the rest of the Territory put together, or 467 acres against 355 acres to express the fact in figures. ()f the remaining 355 acres the Oahu Sugar (co. claims over half, so that these two plantations have 650) acres against 172 reported from the other plantations of the Association.

Practically all the plantations have been active in preliminary work with these canes, and many of them are prepared to rapidly extend certain varieties once the element of doubt is finally removell from these new seedlings. H. $22 \tau$, H 146 and $I I 2 \tau$ are the most widely distributed, each being reported in commercial or experimental areas from 18 plantations, while 10 or more plantations have each of the following under observation: H 20, H 25, H $33, \mathrm{H} 68, \mathrm{H} 69$, H 99, H 109, H 135, H 151 , H 197 and $\mathrm{H} 240$.

On the whole, the further we go, the more of a question this matter of varieties becomes. With two such excellent canes as Lahaina and Yellow Caledonia it might appear to some that undue stress is placed on the new seedlings. But aside from the desirability of replacing excellent varieties with better ones, if they are to be hall, we are confronted with the possibility, however remote it may be, that it may be

\footnotetext{
3 Including Louisiana Siriped, which is supposed to be the same variety.
} 


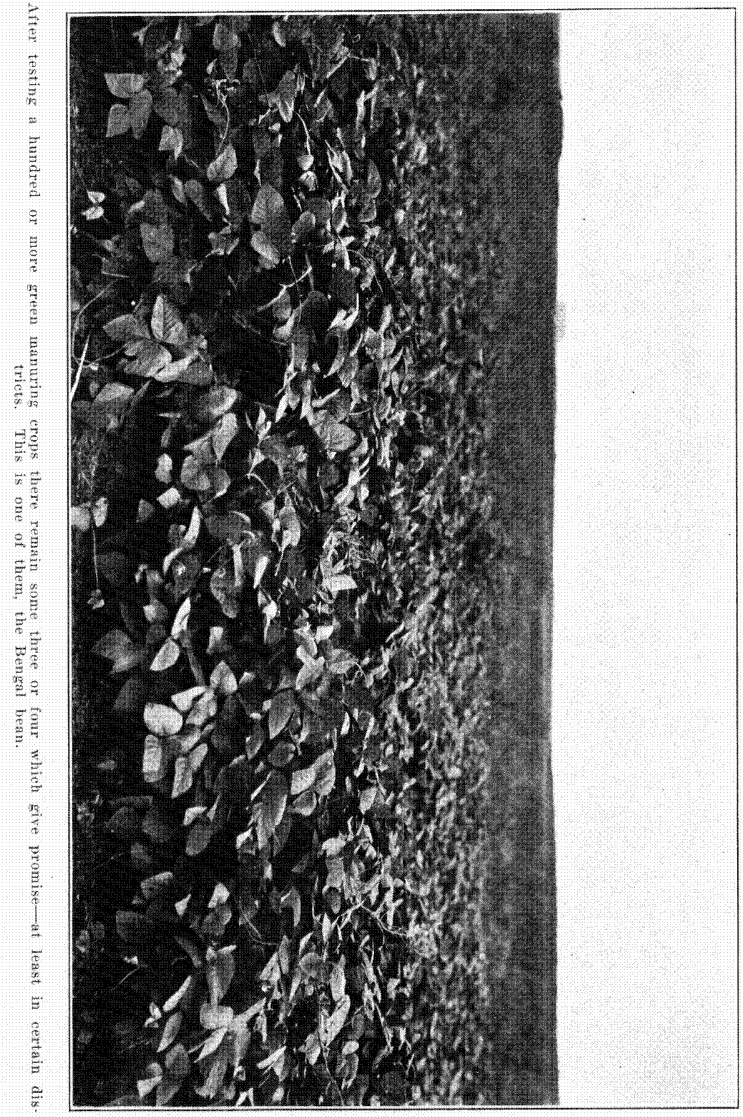


necessary to call others into play to even maintain our present standards. Certain facts in connection with the Lahaina cane appeared in the August number of the Planters' Record to which it may be well to make brief reference here in saying:

$6 * * *$ the records of other sugar cane growing countries show that the Bourbon (Lahaina) cane has run out in the majority of them and its cultivation has had to be largely curtailed or abandoned. The running out has occurred after very varying lengths of cultivation in different countries. It occurred in Queensland as long ago as 1872, when the variety had been there in cultivation only a comparatively few years. Its effect commenced to be marked in the northern West Indian Islands early in the nineties of the last century, probably preceded somewhat in Barbados, where its cultivation had been the most intensive amongst the West Indian colonies, and followed a little later in St. Vincent, where from about 1884 its cultivation had ceased to be intensive. 4

Added to this we know that the Lahaina variety was once largely cultivated in Mauritius and Natal and there is evidence that both Java and Cuba formally utilized it to a wide extent.

The playing out of Lahaina cane on the Island of Hawaii is a familiar matter, and the difficulty experienced with this variety in certain fields on Oahu is becoming generally known.

We do not attempt to say that the cause of the trouble is the same in all these instances. We are not pessimitic enough to predict that Lahaina will not continue to flourish as a standard cane in these Islands for many years to come, or that Yellow Caledonia would not continue to be a good substitute where Lahaina falls by the wayside. But be this as it may, the new varieties offer other baskets into which we may put some of our eggs, and they should be valued for this if for nothing else.

Yet there is the hope that we have found, or that we may find, seedlings which will prove better than either Yellow Caledonia or Lahaina when these canes are at their best. We have a good many figures of a more or less tentative character which encourage this belief. There are several points which will help us to realize it. In the first place we must appreciate the fact that a variety may decline or may improve. Its properties may not be permanently fixed. Therefore in replacing a standard variety, even to a limited degree, we should not rely on one or two seedlings. In preliminary tests it is well not to endeavor to ascertain which of, say, fifteen seedlings is the most promising one; but rather to pick out some five or more canes which may safely be extended to five-acre blocks. It is an easy matter to pass with some of these to fifty-acre lots, and then if any of them are worth planting to fields of several hundred acres the fact will soon assert itself. The idea I mean to convey is that such work should be with the object of eliminating the poorer canes and carrying as many of the remainder as circumstances warrant. But in mentioning these points I am doing little else than citing the example of the plantations which have led in this workan example that will no doubt be largely followed.

4 Record, Vol. IX, p. 468, or West Indian Bulletin, Vol. XIII, No. 2. 


\section{CULTIVATION.}

The methods of cultivation in vogue in the Islands, the actual means of producing a cane crop and bringing it to the factories, have been developed by the plantation managers and their staffs of practiced field men. It is only in a small way that the Experiment Station has rendered service in this all-important work. Even then such assistance has rested largely in noting an excellent method that has been developed on one plantation and suggesting its use in another locality where it could be used to advantage.

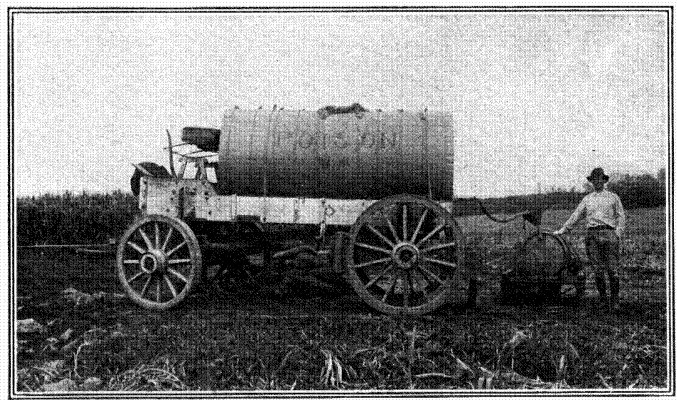

Fighting weeds with arsenic-a supply tank delivers the solution to the fields.

The great variety of field conditions to be found throughout the Islands has resulted in widely varying agricultural practices, many of which have been especially formulated to meet existing circumstances. The field operations of the various localities have to a certain extent met attention from the Station, and a publication has been issued showing some seventy types of agricultural implements which are employed throughout different parts of the Islands. In many cases these tools are peculiar to Hawail and have been designed to accomplish some special work.

The Olaa Sugar Company has, for instance, adopted an original system of controlling the exceptionally heavy weed growth which is common in the districts of heavy rainfall. This is accomplished by the use of arsenic sprays between the rows of cane. According to the nature of the land, the laborers are provided with knapsack tanks to hold the arsenical solution, or else tanks are mounted on sleds which are drawn between the cane 
rows by animals. Arsenic solutions have for several years been utilized in open lands and orchards for killing weeds, but the plan to employ this means to combat foreign growth between the rows of a cultivated crop such as sugar cane was, we believe, first suggested by this Experiment Station. The whole matter of developing the idea and making a practical success of it was. however, the work of the Olaa Sugar Company. The method is simply an economical substitute for a large amount of hand hoeing and implement cultivation which, in view of the watersoaked condition of the fields, was oftentimes a very unsatisfactory task.

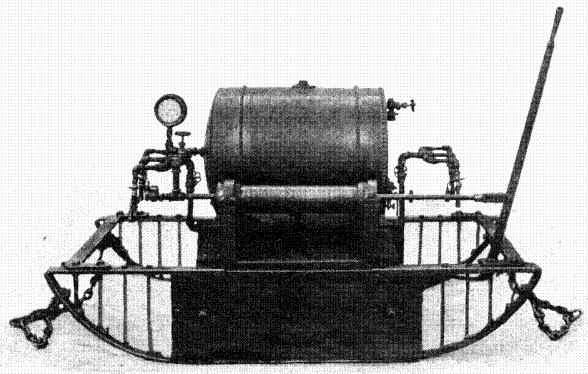

A spraying sled for use between the rane rows.

The innovation is being taken up by several other plantations, but as conditions vary so from one place to another, it is questionable to what extent it will eventually be adopted. The United States Department of Agriculture has become interested in the scheme and is now conducting experiments as to its applicability in cultivating corn in Louisiana and Florida. So, in this, as in numerous instances, the applied science of Hawaii promises to be of more than local value.

\section{FIEID EXPERIMENTS.}

Field experiments hold an important part in the work of the Experiment Station. Take the use of fertilizers, for example. Present-day practices are in a large measure founded upon field testing. These trials are conducted, as a rule, on the plantations 
and are in the main coöperative undertakings between the plantation managers and the agriculturists of the Station. Then, too, there is the Waipio Substation, an area of 135 acres, devoted to field experiments covering a range of subjects. Such matters as the proper formulas for fertilizer mixtures, the amount that can be profitably applied per acre, the best time for application, are some of the issues that can be properly answered only by putting the question to the land itself. Furthermore, these questions must be asked clearly so that there may be no misunderstanding the reply, and this involves care in planning the tests and in clesigning the system of field plots to be employed.

This work extends also to the problems of liming the land, and to the selection of the varieties of cane most suited to a given section, or in the finer points to methods for handling different varieties to gain advantage from their varying characteristics.

Green manuring is another matter which must be handled experimentally in order to find some way of fitting this recognized means of upholding soil fertility to the rather adverse circumstances which the sugar agriculture of Hawaii opposes to its use. In the first place, green manuring has been difficult because there appeared to be no green manuring crop that would resist the ever-present insect pests. After importing all available leguminous plants and testing a hundred or more of them, some three or four remained which give promise, at least in certain districts. Then the question arose of fitting them to the existing agriculture. The heavy irrigation expense, essential in some districts for cane, appeared prohibitive to a crop that returned no direct revenue. The experlient of finding a legume that would thrive between the cane rows was finally resorted to, and this plan is now under trial. Other roundabout means of restoring the heavily-cropped soils are also being investigated. The idle fallowing of land finds no place where acres are scarce and the upbuilding of soils becomes the task of making repairs under full steam ahead.

The agriculture of Hawaii abounds with conditions of this kind - the need of developing unique methods to surmount unique difficulties has long since become a part of the day's work on the sugar plantations of Hawaii. 


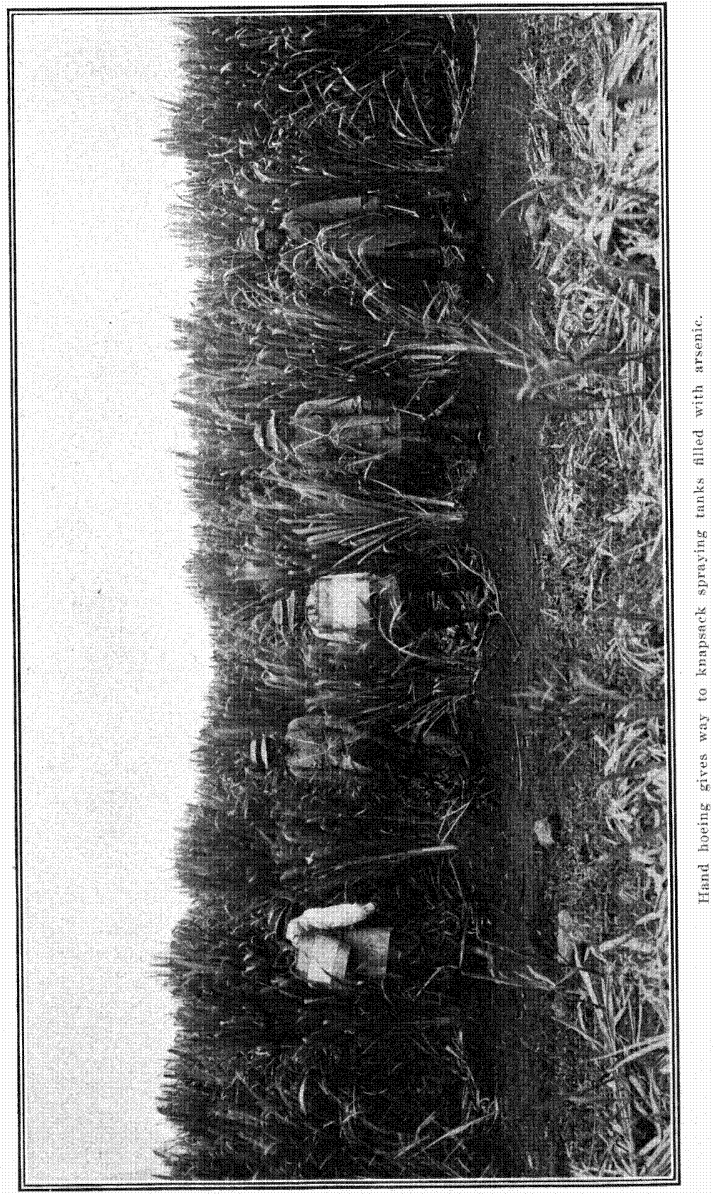




\section{PUBLICATIONS.}

The completed investigations of the Experiment Station of the Hawaiian Sugar Planters' Association are published as technical bulletins. Seventy-eight of these have been issued up to the present time, embracing some four thousand pages in all.

These are divided among three series as follows:

Agriculture and chemistry, 44 bulletins.

Entomology, 13 bulletins ( 21 vols.).

Plant pathology and physiology, 12 bulletins.

These priblications are sent to members of the Hawaiian Sugar Planters' Association; responsible employees on the H. S. P. A. plantations; to seventy federal and state experiment stations, and similar institutions in the United States; twenty federal departments or bureaus in Washington, D. C.; eighteen colleges and universities of high standing in the United States and abroad; fifteen museums and organizations for scientific research in the United States and foreign countries; twenty-one foreign experiment stations; and fifty-seven offices or departments of foreign governments. In addition to this they are also sent, for purposes of review or abstracting, to seventeen leading scientific journals dealing with sugar matters and the various sciences which have an economic bearing thereon. Copies are also sent regularly to scientists in the United States and abroad who are actively engaged in work of a kindred nature.

The following is a list of these bulletins:

\section{Agricultural and Chemical Series.}

A. I Lavas and Soils of the Hawaiian Islands--Walter Maxwell.

B. Miscellaneous Papers-C. F. Eckart.

1. Reiports for the Year 1895-Walter Maxwell.

2. Reports for the Year 1897-Walter Maxwell.

4. Reports for the Year 1898-Walter Maxwell.

$5 . \quad$ Reports for the Year 1899-Walter Maxwell.

6. Reports for the Year 1900-Walter Maxwell.

7. Reports for the Year 1901-R. E. Blouin.

8. Reports for the Year 1902-C. F. Eckart.

9. Reports for the Year 1903-C. F. Eckart.

10. Varieties of Cane-C. F. Eckart.

11. Recent Experiments with Saline Irrigation-C. F. Eckart.

12. Comparative Analyses of Varieties of Cane-C. F. Eckart.

13. Field Experiments with Sugar Cane-C. F. Eckart.

14. Irrigation Experiments of $1905-$ C. F. Eckart. 


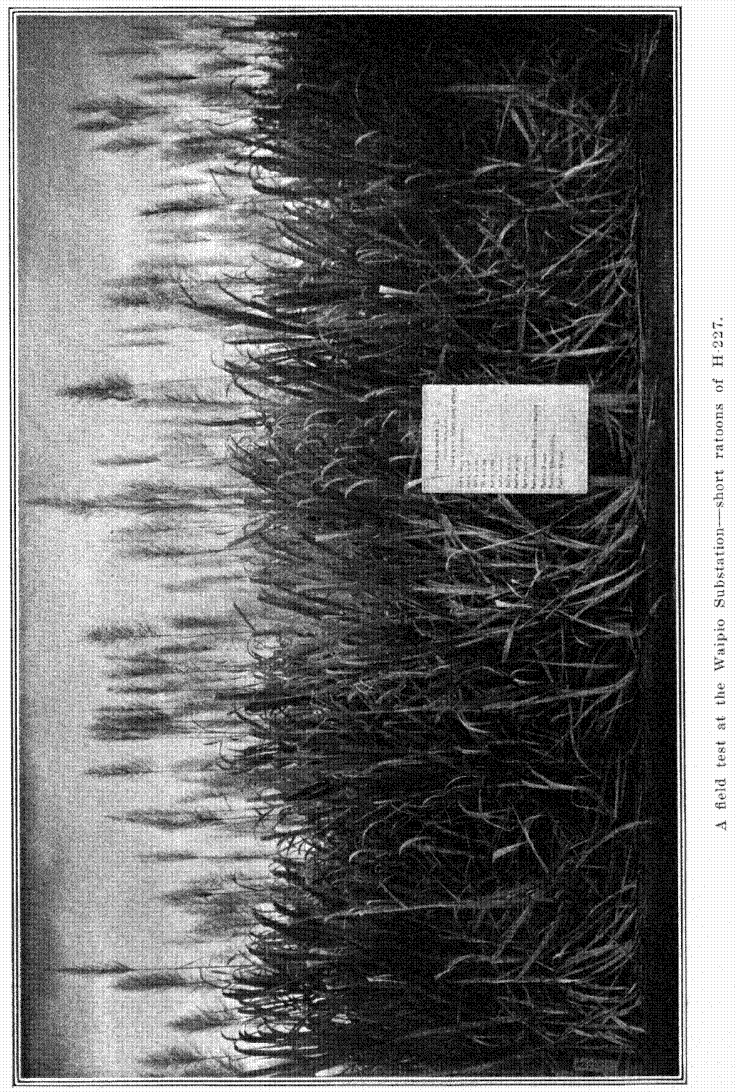


15. Fertilizer Experiments, 1897-1905-C. F. Eckart.

16. The Influence of Stripping on the Yield of Cane and Sugar -C. F. Eckart.

17. Comparative Tests with Varieties of Cane--C. F. Eckart.

18. Hawaiian Waste Molasses-S. S. Peck.

19. Lysimeter Experiments-C. F. Eckart.

20. A Theory of the Extraction of Sugar from MassecuitesNoël Deerr.

21. Evaporator Scale-S. S. Peck.

22. A Theory of the Extraction of Juice by Milling-Noël Deerr.

23. Use of Formaldehyde Solution in Sugar Mills-R. S. Norris.

24. The Deterioration of Sugars on Storage-Deerr and Norris.

25. Results from Stripping Experiments-C. F. Eckart.

26. Varieties of Cane with Special Reference to Nomenclature - Deerr and Eckart.

27. Total Solids in Mill Products by the Refractometer-S. S. Peck.

28. Fermentation of Hawaiian Molasses-Peck and Deerr.

29. The Action of Soluble Fertilizers on Cane Soils-C. F. Eckart.

30. The Influence of the Structure of the Cane on Mill Work in Sugar Factories-Noël Deerr.

31. The Determination of Sucrose in Cane Molasses-Noël Deerr.

32. Bagasse Analysis-Determination of Sugar and MoistureR. S. Norris.

33. Sulphate Scale in Evaporators-S. S. Peck.

34. Some Bio-Chemical Investigations of Hawaiian Soils, with Special Reference to Fertilizing with Molasses-S. S. Peck.

35. The Inversion of Cane Sugar Under the Influence of Acids and Neutral Salts-Noël Deerr.

36. The Effect of High Temperatures cn Cane Sugar in Solution-Deerr.

37. Lysimeter Experiments--S. S. Peck.

38. The Milling of Cane Considered in Relation to the Volume Occupied by the Fiber-Deerr.

39. The Influence of Molasses on Nitrification in Cane SoilsPeck.

40. Heat of Combustion of Bagasse from Hawaiian CaneR. S. Norris.

41. On Available Sugar and a System of Control in the Boiling House-Deerr. 
42. An Experimental Study in Multiple Effect EvaporationNoël Deerr.

43. The Heat Balance of a Cane Sugar Factory-Noël Deerr. 44. The Implements of the Industry-H. P. Agee.

\section{Entomological Series.}

1. Leaf Hoppers and the Natural Enemies.

Introduction.

Part 1. Dryinidae-R. C. L. Perkins.

2. Epipropidae-R. C. L. Perkins.

3. Stylopiclae--R. C. L. Perkins.

4. Pipunculidae--R. C. L. Perkins.

5. Forficulidae, Syrphidae, and HemerobiidaeF. W. Terry.

6. Mymaridae, Platygasteridae-R. C. L. Perkins.

7. Orthoptera, Coleoptera, Hemiptera-O. H. Swezey.

8. Encyrtidae, Eulophidae, Trichogrammidae-R. C. L. Perkins.

9. Leaf Hoppers-Hemiptera-G. W. Kirkaldy.

10. Dryinidae, Pipunculidae, Supplementary - R. C. L. Perkins.

2. Notes on Some Fijian Insects-F. Muir.

3. Leaf Hoppers-Supplement (Hemiptera) - G. W. Kirkaldy.

4. Parasites of Leaf Hoppers--Perkins; Kirkaldy.

5. The Sugar Cane Leaf Roller (Omiodes accepta), with an Account of Allied Species and Natural Enemies-(). H. Swezey.

6. The Hawaiian Sugar Cane Bud Moth (Ereunetis flavistrata), with an Account of Some Allied Species and Natural Enemies-O. H. Swezey.

7. Army Worms and Cut Worms on Sugar Cane in the Hawaiian Islands-Swezey.

8. A Bibliography of Sugar Cane Entomology-G. W. Kirkaldy.

9. On Some New Species of Leaf Hopper (Perkinsiella) on Sugar Cane-Muir.

10. Parasites of Insects Attacking Sugar Cane-R. C. I. Perkins.

11. Parasites of the Family Dryinidae-R. C. L. Perkins.

12. On Some New Species of Leaf Hoppers-Kirkaldy and Muir. 
Pathological Series.

1. The Inspection and Disinfection of Cane Cuttings-N. A. Cobb.

2. Preliminary Notes on the Root Diseases of Sugar Cane in Hawaii-Lewton-Brain.

3. Third Report on Gumming of the Sugar Cane-N. A. Cobb.

4. Some Elements of Plant Pathology-N. A. Cobb.

5. Fungus Maladies of Sugar Cane-N. A. Cobb.

6. Fungus Maladies of Sugar Cane-N. A. Cobb.

7. A Lecture on Rind Disease of the Sugar Cane-L. LewtonBrain.

8. Red Rot of the Sugar Cane Stem-L. Lewton-Brain.

9. The Bacterial Flora of Hawaiian Sugar-L. Lewton-Brain and Deerr.

10. Diseases of the Pineapple-L. D. Larsen.

11. Iliau, an Endemic Cane Disease-H. L. Lyon.

12. Fungi Parasitic upon Insects Injurious to Sugar CaneA. T. Speare. 
. - 


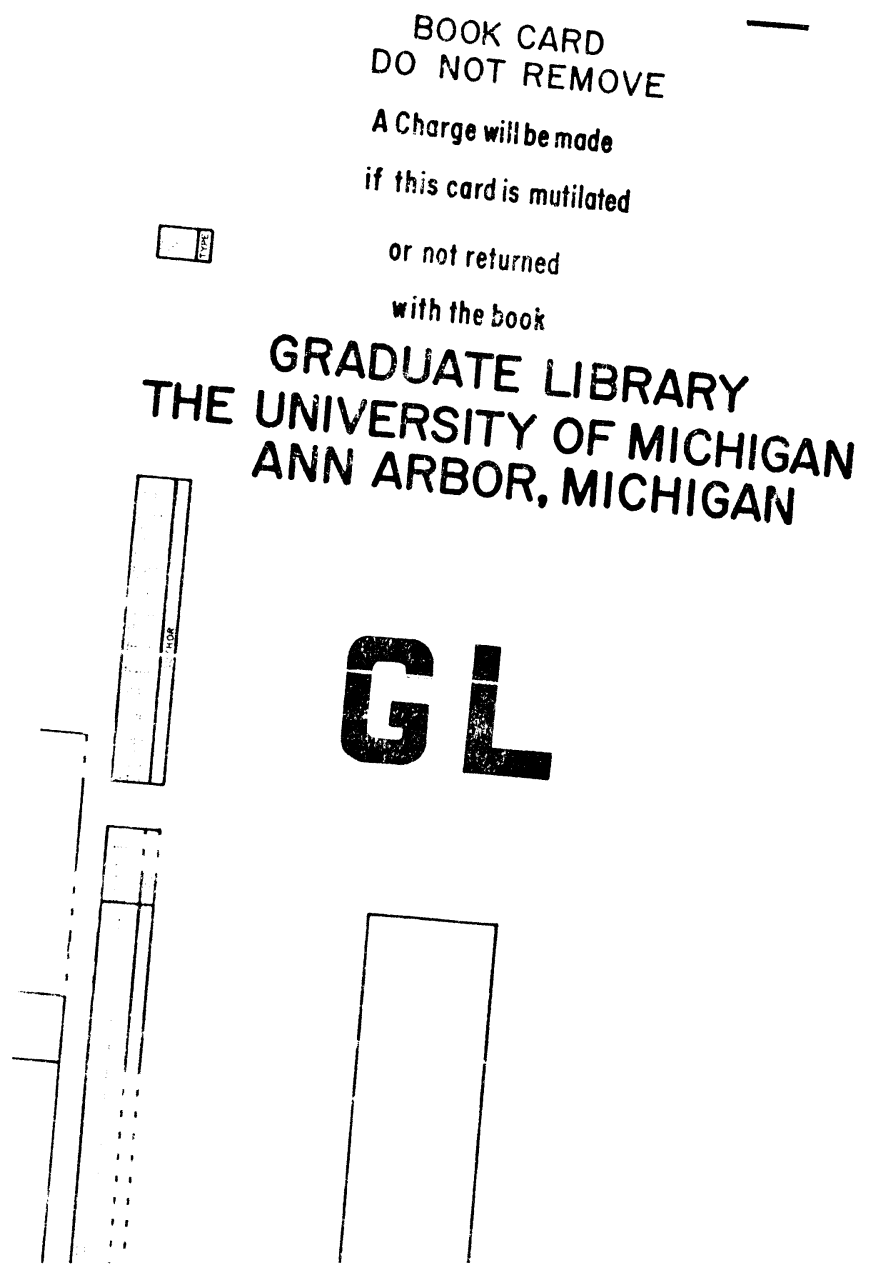

\section{DO NOT REMOVE OR}




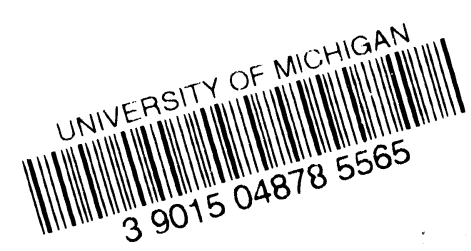

\section{THE UNIVERSITY OF MICHIGAN GRADUATE LIBRARY}

DATE DUE

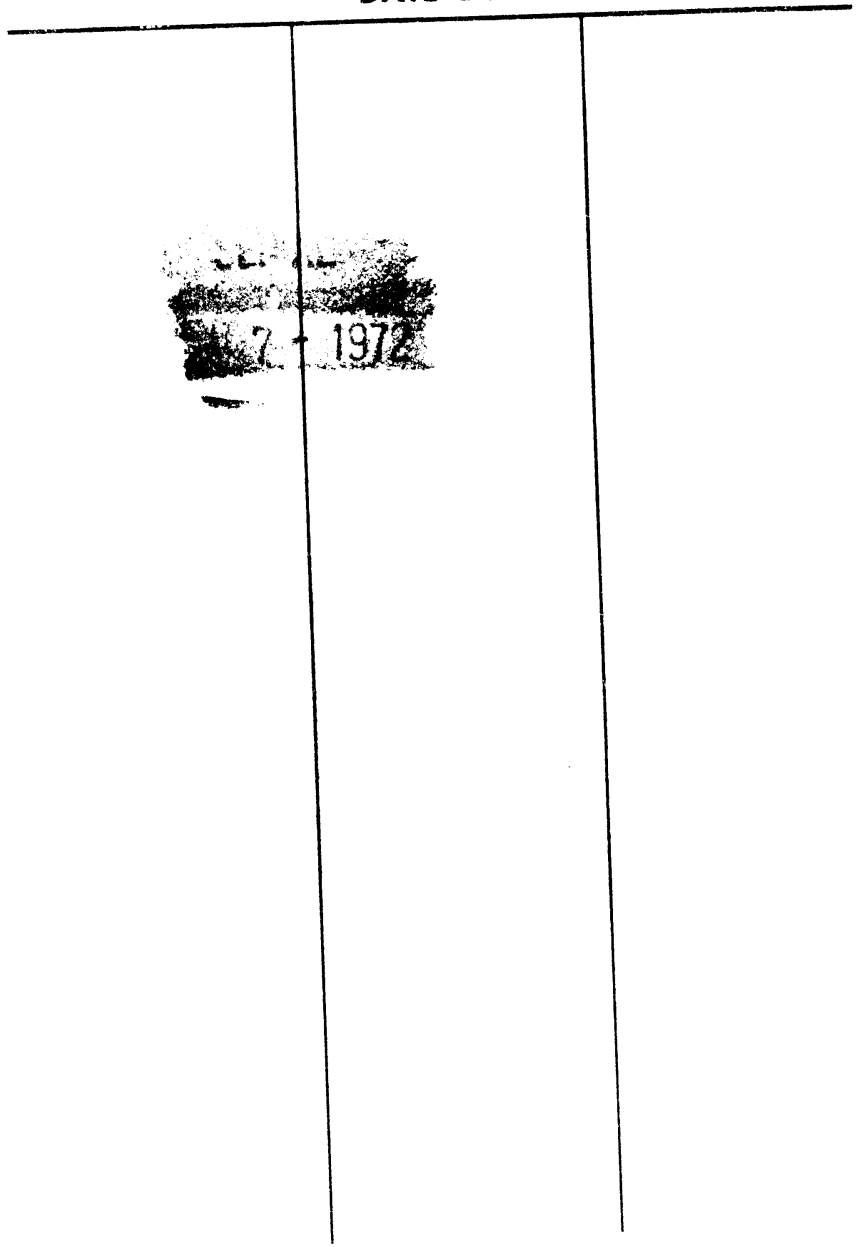




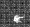

